\title{
Regimes internacionais: teoria e metodologia de análise da efetividade dos regimes ambientais
}

\author{
Flavio Paulo Meirelles Machado' \\ Maurício Sampaio do Santos ${ }^{2}$
}

\section{Resumo}

Este artigo tem como objetivo analisar o que são regimes internacionais e apresentar uma plataforma metodológica de pesquisa para futuras avaliações sobre a efetividade dos regimes ambientais. Primeiro, faz-se um exame da teoria dos regimes sob a ótica de três correntes de pensamento das Relações Internacionais: Realismo, Liberalismo e Cognitivismo. Em segundo, os autores examinam critérios e opções metodológicas para avaliação da efetividade dos regimes ambientais internacionais.

Palavras-chave: Regimes internacionais. Direito ambiental internacional. Teoria da estabilidade hegemônica. Efetividade. Instituições internacionais.

\section{Teoria dos regimes internacionais}

A presente pesquisa examina a Teoria dos Regimes nas Relações Internacionais, expondo-as sob a ótica de três correntes de pensamento das Relações Internacionais. Na primeira parte, pretende-se atender as expectativas de fornecer instrumentos para um diálogo básico sobre conhecimentos teóricos. Em segundo lugar, os autores examinam critérios e opções metodológicas para avaliação da efetividade dos regimes ambientais internacionais. Em seguida, abordam o objetivo central da pesquisa: conciliar as metodologias sobre efetividade de regimes em pequena escala, presentes em inúmeros estudos de caso, com as indagações das Teorias de Relações Internacionais, permitindo assim

\footnotetext{
${ }^{1}$ Advogado. Especialista em Direito Internacional Ambiental pelo Programa das Nações Unidas para Treinamento e Pesquisa (UNITAR).

${ }^{2}$ Bacharel em Relações Internacionais pelo UniCEUB. E-mail: in2deeps@gmail.com.
} 
que futuros acadêmicos tenham mais facilidade na análise de efetividade de certos regimes ambientais.

Os regimes internacionais estão presentes em todas as esferas das relações internacionais. Em suas atividades cotidianas, os diferentes indivíduos encontramse inseridos e fazendo uso de variados regimes internacionais formais e informais. Quando recebem uma carta ou um telefonema internacional, por exemplo, essa simples ação implica na existência prévia de um regime internacional, cuja existência se deve a um anterior e intrincado jogo político, movimentações e mobilizações sociais sem as quais as feições do mundo atual seriam outras.

Os regimes internacionais, apesar de serem um tema controvertido, formam uma categoria básica para o entendimento do Direito Internacional Contemporâneo. A atual conjuntura global evidencia a importância desse tema. De fato, uma das dimensões da globalização é o crescimento das redes de regras e instituições que regulam as relações internacionais.

A globalização possibilitou aos seres humanos a conscientização de que certos atos realizados pelo homem podem afetar não somente a si mesmos, mas, também aos inúmeros atores presentes no meio ambiente de maneira, por vezes, caótica e incontrolável; nos casos mais críticos, até mesmo, irreversíveis.

O que é mais importante de se constatar é que algumas dessas ações do homem e fenômenos da natureza excedem o conceito geopolítico de território: verbi gratia, um problema ambiental em um país, em pouco tempo pode afetar outras nações. Daí a crescente preocupação dos instrumentos jurídicos em regularem essas ações. Por exemplo, a Declaração de Estocolmo de 1972 "expressa a convicção comum de que: o homem [...] tem a solene obrigação de proteger e melhorar o meio ambiente para as gerações presentes e futuras [...]"; "Estados têm [...] obrigação de assegurar-se de que as atividades que se levem a cabo, dentro de sua jurisdição, ou sob seu controle, não prejudiquem o meio ambiente de outros Estados ou de zonas situadas fora de toda jurisdição nacional”s $\mathrm{e}$ "devem assegurar-se de que as organiza-

\footnotetext{
${ }^{3}$ Cf. os neoliberais Keohane e Nye, globalização é a intensificação do que esses autores descrevem como interdependência. De maneira simplória, interdependência significa situações caracterizadas por efeitos recíprocos entre atores em diferentes países.

${ }^{4}$ Declaração de Estocolmo, 1972, Princípio 1.

${ }^{5}$ Ibidem, Princípio 21.
} 
ções internacionais realizem um trabalho coordenado, eficaz e dinâmico na conservação e no melhoramento do meio ambiente."6

No contexto ambiental, verifica-se que a depreciação da camada de ozônio, o aquecimento global e a poluição são problemas globais que não podem ser contidos nem solucionados por um único Estado. Ou seja, muitos dos problemas globais implicam soluções políticas internacionais, tal como, o Protocolo de Quioto, relativo às substâncias que aumentam o efeito estufa.

As inquietações contemporâneas voltam-se para a busca de compreensão e entendimento acerca de uma série de transformações ocorridas em várias dimensões: política, econômica ou ambiental, dentre outras. Nossa sociedade tem sofrido um redimensionamento, fruto não somente das novas tecnologias, sobretudo, dos meios eletrônicos da informação, mas do uso tecnológico baseado em interesses sociais, econômicos e políticos. Isto é, da interação entre o que há de tecnologia disponível e o que as pessoas querem fazer dela, segundo seus valores, crenças e ideais de mundo. ${ }^{7}$

Entende-se aqui que esse fenômeno descrito faz parte da chamada globalização, uma mutação crescente na geopolítica mundial, cujo sintoma mais visível é o constante aumento do entrelaçamento dos povos, envolvendo redes de interdependência continentais, ligadas pela circulação e influência de capital e bens, de informação e ideias, de pessoas e forças e também pelo meio ambiente. ${ }^{8}{ }^{9}$

Essas mudanças foram dinamizadas pelo advento da desregulamentação e liberalização dos Estados no final do século XX, e igualmente pela existência de infraestrutura informacional das telecomunicações e transportes que permitiram

\footnotetext{
${ }^{6}$ Ibidem, Princípio 11.

${ }^{7}$ CASTELLS, Manuel. Manuel Castells: depoimento [maio de 2001]. Entrevistador: Harry Kreisler. Califórnia, EUA, 2001. Conversation with History: Institute of International Relations, UC Berkeley. p. 2. Disponível em: <http:/globetrotter. berkeley.edu/people/Castells/ castells-con0.html>. Acesso em: 16 fev. 2009.

${ }^{8}$ KEOHANE, Robert; NYE, Joseph. Power and interdependence. London: Logman, 2001. p. 229.

${ }^{9}$ Este último é transnacional por excelência. Desde sempre, não respeita qualquer abstração humana de território político, a biosfera não recusa qualquer unidade presente sob seu espectro. O meio ambiente é um sistema fechado com a característica de incluir todas as partes e não isolar qualquer de suas unidades. $\mathrm{O}$ que difere regimes de sistemas é que os regimes são abertos, aceitam a adesão de novos atores, limitando-os somente quanto à sua natureza, verbi gratia, natureza jurídica, natureza regional, natureza social constitutiva.
} 
que um sistema global pudesse funcionar em escala mundial. ${ }^{10}$ Porém, as sociedades não são formadas somente pelos seus desenvolvimentos técnicos e científicos, mas o que se faz com a técnica, em relação com aquilo que somos ou acreditamos que deva acontecer em nosso mundo. Essa relação é construída em termos de identidade ${ }^{11,12}$. Portanto, é uma dialética entre a tecnologia e as estruturas sociais, do eu e das redes. A abordagem de Castells postula "que as sociedades são organizadas em processos estruturados por relações historicamente determinadas de produção, experiência e poder"13.

Uma instituição vista dentro desse novo mundo é o Estado; seu desempenho tem se transformado rapidamente devido ao crescimento do poder de outros atores, o que o obriga a se juntar para tomar decisões que afetam todos e equilibrem as relações para maior controle sobre os fenômenos nacionais e internacionais. Para isso, constitue uma série de instituições, baseadas em Estados Nações, mas também em instituições "supranacionais". Desenvolve um sistema complexo de relações institucionais, com inúmeras formas, mas com certas similaridades ${ }^{14}$

${ }^{10}$ CASTELLS, Manuel. Sociedade em redes. 3. ed. São Paulo: Paz e Terra, 1999. p. 36-37.

${ }^{11}$ Identidade é a união das qualidades inerentes ao ator no agrupamento de atores, corresponde a suas experiências e à sua consciência. É um conjunto de significados, tomados em perspectiva com outros atores, que um indivíduo ou grupo atribuem a si próprio. SARFATI, Gilberto. Teorias de relações internacionais. São Paulo: Saraiva, 2006. p. 261. Já Castells a define como "a fonte de significado e experiência de um povo [...] o processo de construção de significado com base em um atributo cultural, ou ainda um conjunto de atributos inter-relacionados, o(s) qual(ais) prevalece $(\mathrm{m})$ sobre as fontes de significado. [...] é necessário estabelecer distinção entre identidade e [...] papéis. [...] Papéis são definidos por normas estruturadas pelas instituições e organizações da sociedade.[...] identidades constituem fonte de significados para os próprios atores." CASTELLS, Manuel. $O$ poder da identidade. 3. ed. São Paulo: Paz e Terra, 2002. p. 22-23.

${ }^{12}$ CASTELLS, Manuel. Manuel Castells: depoimento [maio de 2001]. Entrevistador: Harry Kreisler. Califórnia, EUA, 2001. Conversation with History: Institute of International Relations, UC Berkeley. p. 2. Disponível em: <http://globetrotter. berkeley.edu/people/ Castells/castells-con0.html>. Acesso em: 16 fev. 2009

${ }^{13}$ Idem. Sociedade em redes. 3. ed. São Paulo: Paz e Terra, 1999. p. 33.

${ }^{14}$ União Européia, NAFTA, MERCOSUL, ASEAN, APEC, CEI, OUA, BSEC, ALADI, CACM, CARICOM. Todas essas são diferenciadas quanto seu grau de integração, cada uma segundo suas possibilidades, mas todas procuram estabelecer relações econômicas para desviar e aumentar o comércio no intuito de incrementar a competitividade, desenvolvimento e participação efetiva no mundo globalizado. 
em todo o mundo. ${ }^{15}$ No mais, o Estado tem um papel para entendimento entre as relações tecnológicas e a sociedade; promove, interrompe ou lidera a inovação tecnológica, e é um fator decisivo, pois organiza as forças sociais dominantes. ${ }^{16}$

Adiante, observa-se que o progresso da técnica deu novas dimensões aos problemas da comunidade. Portanto, há a necessidade de solucionar os problemas mundiais dentro de novas dimensões estabelecidas por uma civilização cada vez mais aperfeiçoada em sua técnica. 17 Castells acredita que, talvez, o problema fundamental dessa questão seja a crise política das instituições responsáveis por gerir essas mudanças. 18 Para o autor, vivemos em um complexo sistema de relações institucionais, uma rede de Estados19, ou melhor, uma complexa rede de interações entre "soberanias compartilhadas", e cuja chave de maior entendimento está nas conexões econômicas geridas paralelamente entre Estados e instituições internacionais (p.ex, FMI, NAFTA, Pacto Andino, BID, Mercosul).

Os Estados operaram dentro de uma rede interativa e ampla. Todo tomador de decisão do processo econômico mundial, por exemplo, tem que interagir com o mercado financeiro internacional, com outros tomadores de decisão, com políticas

${ }^{15}$ CASTELLS, Manuel. Manuel Castells: depoimento [maio de 2001]. Entrevistador: Harry Kreisler. Califórnia, EUA, 2001. Conversation with History: Institute of International Relations, UC Berkeley. p. 2. Disponível em: <http://globetrotter. berkeley.edu/people/ Castells/castells-con0.html>. Acesso em: 16 fev. 2009.

${ }^{16}$ Idem. Sociedade em redes. 3. ed. São Paulo: Paz e Terra, 1999. p. 31.

${ }^{17}$ REINHOLD, Niebuhr. A crise mundial e a responsabilidade dos Estados Unidos. São Paulo: Dominus Editora, 1964. p. 11.

${ }^{18}$ CASTELLS, Manuel. Global governance and global politics. Political Science \& Politics, v. 38, n. 1, p. 9, jan. 2005. Disponível em: <http://www.manuelcastells. info/en/obra_02. htm>. Acesso em: 16 fev. 2009.

${ }^{19}$ Castells difere o temos Estado em rede, network state, do termo de sociedade em rede, network society. Essa é a sociedade onde as principais estruturas e atividades sociais são organizadas sob rede de informações eletrônicas - comunicações. Não são exclusivamente relações sociais em rede. Já historicamente existiram inúmeras outras formas de redes sociais. A novidade é a composição de redes sociais que gerem ou processam informações, usando tecnologia microeletrônica avançada. Nela todos os domínios são afetados por esses padrões de ações locais e, ao mesmo tempo, globalizadas. Culminando, que as relações de poder e a institucionalização dos poderes sociais são constantemente decididas e influenciadas nos campos das comunicações. CASTELLS, Manuel. Communication, power and counter-power in the network Society. International Journal of Communication, v. 1, 2007, p. 238-266. Disponível em: <http://www.manuelcastells.info/en/obra_02.htm>. Acesso em: 16 fev. 2009. 
regulamentárias, e com as instituições nacionais e internacionais que compõem uma meta-rede composta por subunidades ou sub-redes. ${ }^{20}$

Além das instituições clássicas, tais como os Estados, as sociedades e indivíduos também precisam se adaptar a essas novas mudanças, e esse é o caso dos grupos sociais. Dentro de um universo onde flui riqueza, poder e imagens, a formação da identidade - coletiva ou individual, imposta ou construída - é crucial. ${ }^{21} \mathrm{~A}$ razão disso é que essa sociedade em rede tem um poder de influência ${ }^{22}$ imenso. Potencializa a capacidade de ação das unidades dentro dessas relações. Nesse sentido, dentro da visão majoritária dos autores de afinidades acadêmicas marxistas, ${ }^{23}$ existe "uma estrutura de valores e entendimento sobre a ordem das coisas que permeia as entidades estatais e não estatais que tende a subordinar os demais pensamentos"24; é o resultado do técnico aliado à formação das mentes. Isso revela que existe uma relação de forças sociais e materiais que possibilitam que certos valores de certos grupos políticos prevaleçam nas relações sociais.

Castells testifica que redes internacionais são bem potentes, contudo, incluem tão somente os valores que as programam. Levando suas observações ao extremo, a rede capitalista global, que inclui Estados, companhias, regiões, outras redes e pessoas aumenta e reitera o valor de enriquecimento e lucro. Do outro lado, existem atores que resistem à dominação desses valores implementados, muitas vezes usando da própria rede para alcançar significados alternativos

${ }^{20}$ CASTELLS, Manuel. Manuel Castells: depoimento [maio de 2001]. Entrevistador: Harry Kreisler. Califórnia, EUA, 2001. Conversation with History: Institute of International Relations, UC Berkeley. p. 2. Disponível em: <http://globetrotter. berkeley.edu/people/ Castells/castells-con0.html>. Acesso em: 16 fev. 2009.

${ }^{21}$ Ibidem, p. 5.

${ }^{22}$ Capacidade de hegemonia em termos gramscianos, difusão em termos construtivistas e, ainda, poder ideológico nos termos de E.H. Carr.

${ }^{23}$ Por ex. Castells, Cox, Geertz, Gramsci, e outros, não globalistas. É possível fazer a mesma interpretação, mas em outros termos, tal como as categorias de poder ou difusão, incluindo assim, realistas (Susan Strange, Gilpin, Krasner) ou construtivistas (Wendt).

${ }^{24}$ COX, Robert W. Gramsci, hegemony and international relation: an essay in method. In: GILL, Stephen. Gramsci, historical materalism and international relations. Cambrigde: Cambrigde University Press, 1993. p. 50. 
para o modelo,.$^{25}$ ou até mesmo apelando ao radicalismo em busca da extinção do modelo. ${ }^{26}$ Para o autor, a tecnologia em si não é má nem mesmo ruim, mas certamente não é neutra. ${ }^{27}$

Apesar de se ter iniciado o tema, a globalização e seus processos não é a especificidade deste trabalho. Essa breve explanação serve de ponto de partida empírico e não tem a pretensão de esgotar nem debater o tema exaustivamente. $\mathrm{O}$ intuito é usar a globalização como pano de fundo com as muitas interpretações já feitas no mundo acadêmico. Esse dado empírico inclui, dentre muitos outros, objetos chave para nosso tema: economia global e meio ambiente comum; e um fator crucial, a crise de eficiência para lidar com os resultados do choque entre o meio ambiente e os métodos de produção, consumo, valores e instituições relacionadas à economia.

Essa crise fica evidente, quando os movimentos ambientalistas, com apoio de comunidades sistêmicas, ${ }^{28}$ demonstraram que certos meios de produção e consumo extrapolam a capacidade de o meio ambiente permanecer saudável e questionam nossa cultura desenvolvimentista traduzida em escolhas políticas inviáveis a longo prazo.

O que podemos dizer que ficou claro ao mundo, é que há uma contradição entre nosso desenvolvimento e a capacidade do planeta em manter a vida. Vislumbra-se, portanto, que talvez um processo de mudanças históricas fosse necessário.

Para Robert Cox, embora não comentando o problema ambiental específico, mas dissertando sobre as contradições históricas como um todo, embora restringidas pela estrutura prevalecente, essas são o ponto de partida para trans-

${ }^{25}$ CASTELLS, Manuel. Manuel Castells: depoimento [maio de 2001]. Entrevistador: Harry Kreisler. Califórnia, EUA, 2001. Conversation with History: Institute of International Relations, UC Berkeley. p. 2. Disponível em: <http://globetrotter. berkeley.edu/people/ Castells/castells-con0.html>. Acesso em: 16 fev. 2009.

${ }^{26}$ Para maior entendimento sobre os movimentos contra-hegemônicos recomenda-se o artigo do DEVETAK, Richard. Critical theory. In: BURCHILL, Scott; LINKLATER, Andrew. Theories of international relations. New York: St. Martin's Press, 1995.

${ }^{27}$ CASTELLS, Manuel. Sociedade em redes. 3. ed. São Paulo: Paz e Terra, 1999. p. 81.

${ }^{28}$ Redes de profissionais com reconhecida especialização e competência na área de conhecimento que contribuem para responder um problema central em questão. Para mais esclarecimentos ver: HASS, P. M. Introduction: epistemic communities and international policy coordination. International organization, [S.1.], v. 46, n. 1, 1992. 
formação mediante a ação, na medida em que a mudança histórica é consequência da atividade humana. ${ }^{29}$

Para se alcançar uma mudança no mundo objetivo, é importante compreender que o processo de transformação histórico é feito pela reconstrução da intersubjetividade coletiva. ${ }^{30} \mathrm{Em}$ outras palavras, onde há ideias sobre o mundo real incompatíveis com a necessidade de se solucionar um determinado problema no mundo, detecta-se a inadequação das estruturas fundadas sobre visão intersubjetiva e, consequentemente, busca-se uma reestruturação ou nova estrutura capaz de solucioná-los.

Seguindo a mesma linha de raciocínio, Castells apresenta que uma nova sociedade surge se uma transformação estrutural puder ser reconhecida nas relações de produção, de poder e de experiência. "Essas transformações conduzem a uma modificação também substancial das formas sociais de espaço e tempo e ao aparecimento de uma nova cultura."31

\footnotetext{
${ }^{29}$ Não é saudável para as ciências sociais, entretanto, admitir que toda a história seja um processo inerentemente evolutivo, como crêem os liberais clássicos, ou naturalmente resultado de ações humanas revolucionarias como entendem os marxistas clássicos. A confiança humana nesse parâmetro é ingênua, mas tal idéia tem ganhado força porque é parcialmente verdadeira tendo-se em mente que todo o tremendo avanço da ciência, tecnologia e inteligência humanas parecem justificar tal crença. O progresso, para os fisiocratas é a remoção de todos os impedimentos históricos da operação das leis da natureza. NIEBUHR, Reinhold; HARRY, Davis R.; GOOD, Robert C. (Ed.). Reinhold Niebuhr on politics. New York: Charles Scribner's Sons, 1960. p. 19. Sempre haverá progresso na história, muito mais no sentido de evolução do que no de melhoria, o que retira do fator progresso um bocado da fé cega que algumas ideologias atribuem a esse quesito afinal, o progresso não se identifica necessariamente com progresso moral. Para cada avanço surgem e ainda surgirão novas questões, novas implicações morais, novos desdobramentos imprevisíveis e incontroláveis. Ibidem, p. 21. Afinal, além de não poder ser feita com vistas ao futuro, sob o risco de tornar-se mera futurologia e profetização sem base, a análise histórica faz sentido somente quando em retrospectiva. "A maioria dos seres humanos atua como os historiadores: só em retrospectiva reconhece a natureza de sua experiência." HOBSBAWN, Eric. Era dos extremos. São Paulo: Companhia das Letras, 2008. p. 253. Ao comentar sobre as tentativas de predição histórica, o autor, fazendo alusão a eventos como corridas de cavalos, destaca que só se pode relatar ou analisar aquelas já ganhas ou perdidas. De qualquer modo, continua ele até com certa ironia, sejam quais fossem suas qualificações, ou acúmulo de acertos para os seus palpites, nos últimos tempos o desempenho dos adivinhos mostrou-se tão pífio que somente governos e institutos de pesquisa econômica ainda mantêm, ou alardeiam manter a confiança nisto. Ibidem, p. 15.

${ }^{30}$ COX, Robert W. Rumo a uma concepção pós-hegemônica de ordem mundial: reflexões sobre a relevância de Ibn Kaldun. In: ROSENAU, James N; CZEMPIEL, Ernst-Otto. Governança sem governo: ordem e transformação na política mundial. Brasília: Ed. UnB, 2000. p. 191.

${ }^{31}$ CASTELLS, Manuel. Fim do milênio. 4. ed. São Paulo: Paz e Terra, 2007. p. 416.
} 
Assim, os modelos precisam ser reordenados para novamente contarem com consensos intersubjetivos e, ainda que, como diria Kuhn, ${ }^{32}$ não seja possível o acúmulo de conhecimento entre paradigmas distintos à cumulatividade do conhecimento, dessa maneira, se dá em nível metateórico.

Em suma, se pretendemos beneficiar a todos, deve haver um processo não-excludente de gestão global. A necessidade de que esse processo se torne regulamentado fica clara. Conferir certa segurança às relações internacionais envolve a criação de normas e certificar-se de que os Estados e demais atores como: indivíduos, empresas, organizações internacionais e ONG's - ou seja, os componentes que são percebidos na dita sociedade de rede - comprometamse e venham a cumpri-las. Entretanto, a comunidade internacional não tem poder de polícia. Isso, diferentemente dos sistemas internos, impossibilita a implementação de normas e sanções da maneira como conhecemos em nossos territórios.

Destarte, é importantíssima a complacência dos Estados a aderir a leis internacionais. E é evidente a necessidade de se utilizarem mecanismos e técnicas que possam atrair todos os atores a anuirem aos valores ambientais. São os incentivos percebidos pelos atores que os farão aquiescer aos regimes. No mais, o incentivo proposto pelo regime é o que permite aos atores identificarem-se com os valores estabelecidos e aderirem ao regime.

Por isso, afirma-se que os maiores desafios políticos que os governos devem enfrentar são, de certa forma, os problemas coletivos, os quais exigem soluções em conjunto. ${ }^{33}$ É dentro dessa perspectiva de busca de soluções em conjunto que os Estados recorrem aos regimes internacionais, que nada mais são do que mecanismos internacionais que visam solucionar um problema específico com a participação conjunta de vários atores internacionais. Já os regimes ambientais internacionais são meios de adequar ações estatais para se alcançar uma efetividade prática que resolva um problema ambiental.

\footnotetext{
${ }^{32}$ KUHN, Thomas Samuel. The structure of scientific revolution. 3. ed. Chicago, IL: University of Chicago Press, 1996. p. 162-164.

${ }^{33}$ UNDERDAL, Arild. One question, two answers. In: MILES, Edward L. et al. Environmental regime effectiveness: confronting theory wi th evidence. Massachusetts: The MIT Press, 2002. p. 3.
} 
Não se pode repelir ou controlar a totalidade dos fenômenos naturais, nem mesmo a criação e difusão de novas tecnologias, tampouco prever com precisão absoluta os impactos de seu uso pelos seres humanos. A Lei sendo mais estática apresenta dificuldades de acompanhar os desdobramentos das mudanças sociais. Por sua vez, em geral, os regimes são maleáveis, apesar de implicarem, às vezes, em altos custos financeiros, podem se reordenar de modo mais versátil para se adequarem às mudanças ocasionadas pelas configurações da sociedade atual. ${ }^{34}$

Ainda assim, é prudente ressaltar que os regimes com seus arranjos políticos e ideologias conservadoras de manutenção do status quo também podem ter um impacto negativo e causar problemas ao não conseguirem acompanhar as novas demandas provenientes de novas necessidades e, desse modo, tornando-se menos atrativas para os atores. E os regimes altamente mutáveis falham em sua capacidade de ser percebidos como a instância correta para tomada de decisões sobre o tema em questão e, assim, falham em manter a habilidade de frear as contradições e se adaptar as necessidades.

Resta verificar qual é o grau de efetividade das ações tomadas para solucionar os problemas internacionais. É nesse quesito que entra a importância do mundo acadêmico para avaliar esses mecanismos e onde reside a necessidade de se criarem métodos objetivos para avaliação e compreensão dos regimes internacionais. É uma busca coletiva de resolução da crise de eficiência: problemas que conotam resoluções adequadas de grandes temas ambientais.

\footnotetext{
${ }^{34}$ YOUNG, Oran R. Why is there no unified theory of environmental governance? Presented at the commons in an age of globalization, the ninth Conference of the International Association for the Study of Common Property, Victoria Falls, Zimbabwe, June 17-21, 2002. Disponível em: <http://dlc.dlib.indiana.edu/ archive/00000943/>. Acesso em: 19 fev. 2009.
} 


\subsection{Conceito de regimes internacionais ${ }^{35}$}

As duas definições de regimes internacionais mais utilizadas são as de Young e de Krasner. Para o primeiro, regimes internacionais são "Instituições sociais que consistem de acordos em princípios, normas, regras, procedimentos e programas que governam as interações dos atores em determinadas áreas [issue areas]."36

Similarmente a esse conceito, aponta Krasner: "Regimes internacionais são definidos como princípios, normas, regras e procedimentos de tomada de decisão, sobre os quais as expectativas dos atores convergem em uma determinada área temática." ${ }^{37}$

Congruente a isso, Krasner explica que:

Os princípios são crenças sobre fatos, causalidades e retitude. As normas são padrões de comportamento definidos em termos de direitos e de obrigações. As regras são prescrições ou proscrições específicas para ação. Os procedimentos de tomada de decisão são práticas para formular e implementar a ação coletiva. ${ }^{38}$

\footnotetext{
${ }^{35}$ Os Regimes são amplamente analisados pelos mais diversos campos de estudos das Relações Internacionais. A formulação da Teoria de Regimes Internacionais foi influenciada por Krasner em grande escala, todavia nem todos os autores concordam com sua definição de regimes. Até pessoas que contribuíram para o volume de seu livro chamado International Regimes possuem visões diferentes da do autor. Também é importante ressaltar que o conceito de "regime internacional", segundo os principais autores sobre o tema, surgiu de artigos do John Gerard Ruggie. Contudo, ainda há uma incerteza quanto a isso, pois o termo também é atribuído a Susan Strange. De fato, o que ocorre é que ainda existem muitas críticas quanto o caráter "novo" do conceito de regime, alguns autores dizem que "regime" é somente mais uma nomenclatura para organizações internacionais ou instituição internacional como defende Young. Ruggie lembra, endossado pelos autores deste texto, que as organizações internacionais (instituições), por exemplo, a ONU, não se restringem a áreas específicas, enquanto os regimes por definição são restritos a temas determinados. HASENCLEVER, Andreas; MAYER, Peter; RITTBERGER, Volker. Theories of international regimes. Cambridge: Cambridge University Press, 2004. p. 8-11. Além disso, o que se observa nos conceitos para regimes apresentados neste trabalho é que sua definição apresenta elementos tanto de natureza política, quanto de natureza jurídica. A relação entre o Direito Internacional e os regimes é contestada, mas Réus-Smit sugere que o Direito Internacional é muito mais amplo que somente regimes. Ele associa regimes com instituições jurídicas internacionais aplicáveis a uma determinada área. REUS-SMIT. International Law. In: BAYLIS, John; SMITH, Steve. The globalization of world politics. New York: Oxford, 2006. p. 352.

${ }^{36}$ LEVY, Marc; YOUNG, Oran; ZÜRN, Michael. The study of international regimes. [S.l.: s.n.], 1995. Tradução e colchetes são de nossa responsabilidade.

${ }^{37}$ KRASNER, Stephen D. Structural causes and regime consequences: regimes as intervening variables. In: KRASNER, Stephen D. (Ed.). International regimes. Ithaca: Cornell University Press, 1983. p. 185. Tradução de nossa responsabilidade.

${ }^{38}$ Ibidem, p. 186.
} 
Para Jervis, outra referência no assunto, a noção de regime engloba princípios e normas. Sua função utilitária é a de maximizar a noção de obrigações generalizadas (gerais). Um desses princípios é o da reciprocidade dos atores, ou seja, quando um ator adota o regime, sacrifica-se o interesse nacional de curto prazo na expectativa de que os demais atores façam o mesmo, embora esses ainda não se encontrem obrigados. ${ }^{39}$

Além disso, segundo a visão majoritária ${ }^{40}$, regime é algo mais permanente do que simples acordos ou tratados, os quais estão sujeitos a mudanças dos interesses nacionais ou da balança de poder ${ }^{41}$.

Comparados aos tratados, os regimes implicam numa maior limitação da liberdade de ação dos governos. Quando um Estado adere a um regime, esse passa a realizar sua política conforme o determinado pelo regime. As ações desse Estado passam a convergir com a natureza do regime. Em termos gerais, a Parte passa a aceitar determinados valores do regime e constitui um conjunto de instituições com o poder de pôr em prática o estabelecido entre as Partes, garantindo assim, a repetição dos comportamentos desejados. Mesmo assim, o regime não pode ser visto como a única fonte de ação dos atores, pois é óbvio que fatores externos aos regimes podem vir a influenciar ou comprometer sua estrutura.

${ }^{39}$ JERVIS apud Ibidem, p. 187.

${ }^{40}$ Susan Strange iniciou uma crítica sobre a polissemia do termo regime, afirmando que o termo tem diferentes significados para diferentes autores. Suas críticas ecoaram em Young, Krasner, Ruggie, Keohane, Nye, Hass, Kratochwil. A partir desses autores, chegouse a um "consenso majoritário" entre as diferentes visões de que regime é algo mais que um tratado. HASENCLEVER, Andreas; MAYER, Peter; RITTBERGER, Volker. Theories of international regimes. Cambridge: Cambridge University Press, 2004. p. 7-9. Para diferenciação entre organizações internacionais, regimes internacionais e governança global, ordem internacional e sociedade internacional recomenda-se: BARROS-PLATIAU, Ana Flávia; VARELLA, Marcelo Dias; SCHLEICHER, T. Rafael. Meio ambiente e relações internacionais. Revista Brasileira de Política Internacional, [S.1.], p. 100-130, 2004.

${ }^{41}$ Um exemplo disso seria o princípio de Direito Internacional rebus sic stantibus que, segundo Carr, significa que: "estaria implícita em todo tratado, ou seja, que as obrigações de um tratado só teriam eficácia, frente ao direito internacional, enquanto as condições que prevaleciam à época da conclusão do tratado continuassem." CARR, Edward H. Vinte anos de crise. 2. ed. Brasília: Ed.Unb, 2001, p. 236. 
Finalmente, os regimes internacionais, em teoria, além de desempenharem papéis importantes, tais como, padronização de atividades, reduzem a incerteza e a insegurança; estabilizam as expectativas mútuas futuras; minimizam os custos de transação; produzem informações; preveem um conjunto de regras e asseguram a repetição das interações. No quadro abaixo há, de forma resumida e didática, exemplos de regimes. Ressalve-se que há ainda outros regimes que não foram mencionados.

\begin{tabular}{|c|c|c|c|}
\hline Área: & Sigla: & Nome: & Objetivo: \\
\hline Segurança & TNP & $\begin{array}{l}\text { Tratado de não- } \\
\text { Proliferação } \\
\text { Nuclear }\end{array}$ & $\begin{array}{c}\text { Limitar a } \\
\text { proliferação de } \\
\text { armas nucleares }\end{array}$ \\
\hline Segurança & $\begin{array}{l}\text { TRATADO DE } \\
\text { TLATELOLCO }\end{array}$ & $\begin{array}{c}\text { Tratado de } \\
\text { Proibição de } \\
\text { Armas Nucleares } \\
\text { na América } \\
\text { Latina e Caribe }\end{array}$ & $\begin{array}{c}\text { Criar uma zona } \\
\text { livre de armas } \\
\text { nucleares }\end{array}$ \\
\hline $\begin{array}{l}\text { Segurança } \\
\text { Coletiva }\end{array}$ & OTAN & $\begin{array}{c}\text { Organização } \\
\text { do Tratado do } \\
\text { Atlântico Norte }\end{array}$ & $\begin{array}{c}\text { Organizar } \\
\text { segurança coletiva }\end{array}$ \\
\hline Econômica & GATT/OMC & $\begin{array}{l}\text { Acordo Geral } \\
\text { de Tarifas e } \\
\text { Comércio/ } \\
\text { Organização } \\
\text { Mundial do } \\
\text { Comércio }\end{array}$ & $\begin{array}{c}\text { Regular e } \\
\text { promover } \\
\text { comércio } \\
\text { internacional }\end{array}$ \\
\hline Econômica & FMI & $\begin{array}{l}\text { Fundo Monetário } \\
\text { Internacional }\end{array}$ & $\begin{array}{l}\text { Cooperação } \\
\text { monetária/ } \\
\text { estabilidade } \\
\text { financeira }\end{array}$ \\
\hline Desenvolvimento & BIRD & $\begin{array}{c}\text { Banco } \\
\text { Internacional } \\
\text { para a } \\
\text { Reconstrução e o } \\
\text { Desenvolvimento }\end{array}$ & $\begin{array}{c}\text { Reduzir pobreza/ } \\
\text { promover o } \\
\text { desenvolvimento }\end{array}$ \\
\hline Comunicação & UPU & $\begin{array}{l}\text { União Postal } \\
\text { Internacional }\end{array}$ & $\begin{array}{c}\text { Coordenar } \\
\text { Serviços Postais }\end{array}$ \\
\hline
\end{tabular}




\begin{tabular}{|c|c|c|c|}
\hline Transportes & OMI & $\begin{array}{c}\text { Organização } \\
\text { Marítima } \\
\text { Internacional }\end{array}$ & $\begin{array}{c}\text { Segurança } \\
\text { marítima e } \\
\text { à eficácia da } \\
\text { navegação }\end{array}$ \\
\hline Finanças & BASILÉIA II & $\begin{array}{c}\text { Acordo de Capital } \\
\text { de Basiléia }\end{array}$ & $\begin{array}{c}\text { Supervisão } \\
\text { da atividade } \\
\text { bancária/ } \\
\text { capital/ mercado } \\
\text { financeiro }\end{array}$ \\
\hline Crime & \multirow{2}{\text{Transnacional}}{} & $\begin{array}{c}\text { Convenção } \\
\text { contra o Crime } \\
\text { Organizado } \\
\text { Transnacional }\end{array}$ & $\begin{array}{c}\text { Combater o crime } \\
\text { transnacional }\end{array}$ \\
\hline
\end{tabular}

\subsection{Perspectivas teóricas}

Uma superabundância de teorias emergiu para explicar a natureza, função e importância dos regimes internacionais. Krasner em seus estudos propõe separá-las didaticamente em três correntes ${ }^{42}$ para a Teoria de Regimes Internacionais: a estrutural tradicional, a estrutural modificada e a grociana (ou cognitivista). ${ }^{43}$

Alerta-se que a diferença basilar entre as três escolas de pensamento é não tanto as disputas internas de cada uma delas - cujo debate importa para o desenvolvimento da própria escola -,mas sim, nomeadamente, no grau de "institucionalismo" ${ }^{44}$ que atribuem aos regimes, ou seja, a visão que cada uma delas confere aos regimes como

\footnotetext{
${ }^{42}$ Outros autores as separam em neorrealistas, neoliberais, e cognitivas. Hasenclever separa em teorias baseadas no poder, teorias baseadas no interesse, e teorias baseadas no conhecimento. Todas essas divisões são similares e apesar de uma pequena diferença técnica muito detalhada que não importará em falsas compreensões do leitor sobre o tema e por isso, deixaremos de mencionálas. No mais, existem ainda diferenças intraescolares, ou seja, entre os próprios realistas, liberais, e grocianos em cada uma de suas escolas.

${ }^{43}$ KRASNER, Stephen D. Structural causes and regime consequences: regimes as intervening variables. In: KRASNER, Stephen D. (Ed.). International regimes. Ithaca: Cornell University Press, 1983. p. 190.

${ }^{44}$ Krasner define institucionalismo como "a extensão em que o comportamento se conforma às estruturas, isto é, com um conjunto particular de princípios, normas, e regras - e 'persistência [resiliência] ou durabilidade' - com a extensão em que um conjunto particular de princípios, normas, e regras persiste durante um período de tempo em face às mudanças". Idem. Sovereignty: organized hypocrisy. New Jersey: Princeton Press, 1999. p. 56. Tradução nossa.
} 
importantes ou não, para o sistema internacional. Esse debate baseia-se no grau de efetividade dos regimes e aprofunda-se quando é observada a possibilidade do diálogo interparadigmático. ${ }^{45}$

A primeira das separações é caracterizada pelo uso do paradigma da Escola Realista das Relações Internacionais ${ }^{46}$. É representada por Kenneth Waltz, John Mearsheimer, Joseph M. Grieco, Robert Gilpin, Stephen Krasner, Susan Strange. Esta última autora acredita que o conceito de regime seja inútil ou, pelo menos, seja uma interpretação errônea da realidade internacional e se, por acaso, eles realmente existem, esses esconderiam a verdadeira cena internacional, ou seja, as relações de poder e interesses nacionais. ${ }^{47}$ Normas ou regras podem persistir no tempo, todavia, com impacto limitado no comportamento factual dos agentes. Atores declaram uma coisa e fazem outra. A identidade pessoal ou aquela identidade que demonstram são influenciadas por instituições, mas o real comportamento é respaldado por uma lógica de ações e consequências. ${ }^{48}$

Para o Realismo, os atores internacionais possuem interesses próprios, os Estados, unidades básicas das relações internacionais, competem entre si pelo poder, e todo sistema de acordos internacionais está suscetível à balança de poder $^{49}$ e aos interesses nacionais. Normalmente, Estados observam e se

${ }^{45}$ HASENCLEVER, Andreas; MAYER, Peter; RITTBERGER, Volker. Theories of international regimes. Cambridge: Cambridge University Press, 2004. p. 2.

${ }^{46}$ Segundo Martin Griffiths, Krasner é um autor realista [estrutural] principalmente quanto ao seu pensamento conclusivo a respeito dos regimes. Quanto a essa afirmativa, Griffiths escreve que: a “[...] conclusão da análise realista de Krasner é que a tentativa de estabelecer regimes como meio de superar, ou até mesmo atenuar os efeitos da anarquia provavelmente não vai funcionar. A existência de regimes universais não pode disfarçar as diferenças de poder nas relações internacionais, e tais regimes tampouco conseguem alterar a importância da soberania do Estado. Em vez disso, fornecem um cenário estrutural em que os choques entre o norte e o sul são inevitáveis." GRIFFITHS, Martin. 50 grandes estrategistas das relações internacionais. São Paulo: Contexto, 2004. p. 59.

${ }^{47}$ STRANGE apud KRASNER, Stephen D. Structural causes and regime consequences: regimes as intervening variables. In: KRASNER, Stephen D. (Ed.). International regimes. Ithaca: Cornell University Press, 1983. p. 190.

${ }^{48}$ Idem. Sovereignty: organized hypocrisy. New Jersey: Princeton Press, 1999. p. 57.

${ }^{49} \mathrm{~A}$ balança de poderes consiste em analisar, com bom senso e raciocínio, os poderes entre os Estados, observando os possíveis resultados de um confronto, através da consideração de potenciais militares, econômicos, diplomáticos dentre outros, dos envolvidos. 
conduzem pelos caminhos do Direito Internacional, não porque são bons, mas porque o Direito Internacional promove seus objetivos. ${ }^{50}$

Susan Strange ressalta que o termo é baseado em estruturas autoritárias e que os regimes representam o governo de uma sociedade por uma pessoa, uma dinastia ou um grupo que usa efetivamente seu poder sobre o restante da sociedade. $^{51}$

Os Realistas, com noções baseadas em poder, assumem o conceito de que os Estados agem em termos de ganhos absolutos, mas enfatizam os estudos sobre regimes nas considerações sobre ganhos relativos - entendidos como aquilo que elas podem ou não atingir na política internacional - e como essas relações de poder amortizam a efetividade ou robustez dos regimes internacionais. ${ }^{52}$ É uma análise ainda baseada na pressuposição de que os atores são racionais. ${ }^{53}$

Portanto, diante disso, Grieco aponta que as instituições internacionais são incapazes de mitigar os efeitos da anarquia que restringe a cooperação interestatal. O Realismo apresenta uma análise pessimista sobre a cooperação e a capacidade dos regimes internacionais. ${ }^{54}$

A segunda corrente, o estruturalismo modificado, é uma posição intermediária entre o posicionamento clássico da escola Liberal e da escola Realista.

${ }^{50}$ VIOTTI, Paul R; KAUPI, Mark V. International relations theory: realism, pluralism, globalism, and beyond. 3. ed. Boston: Prentice Hall, 1998. p. 55-61.

${ }^{51}$ STRANGE, Susan apud SANTANA, Leonardo Dias. As mudanças climáticas e os regimes internacionais. Brasília: [s.n.], 2004. Tradução nossa.

52 HASENCLEVER, Andreas; MAYER, Peter; RITTBERGER, Volker. Theories of international regimes. Cambridge: Cambridge University Press, 2004. p. 3 (ou, p. 211).

${ }^{53}$ Os realistas clássicos proclamam que o comportamento estatal é racional. O que está por trás disso é que os Estados são guiados pela lógica do interesse nacional definido em termos de sobrevivência, poder e capacidades relativas. Uma política externa racional é capaz de minimizar riscos e maximizar benefícios. O interesse nacional varia conforme as circunstâncias, entretanto, as semelhanças entre as motivações dos Estados permitem uma hipótese racional, prever a lógica do jogo e evitar distorções sobre preferências ideológicas das unidades. HOLSTI, Ole R. Theories of international relations and foreign policy: realism and its challengers. In: KEGLEY JR, Charles W. Controversies in international relations theory: realism and its neoliberal challenge. California, USA: Thompson, 1995. p. 37.

${ }^{54}$ GRIECO, Joseph. M. Anarchy and the limits of cooperation. In: KEGLEY JR, Charles W. Controversies in international relations theory: realism and its neoliberal challenge. USA: Thompson, 1995. p. 151. 
Pode ser observada nos trabalhos de Keohane, Nye e Stein e, hoje, é a principal corrente sobre regimes internacionais. ${ }^{55}$

Esses autores não são insensíveis quanto aos diferenciais de poder, já que consideram também em suas análises axiomas estruturalista-realistas e noções liberais de economia.Aceitando o paradigma básico do Realismo, concordam que dentro da ordem anárquica internacional existam diferenciais de poder, que os Estados são soberanos e buscam seus próprios interesses. Contudo, afirmam que a função básica dos regimes é a coordenação do comportamento estatal. ${ }^{56}$

Dentro dessa perspectiva, os regimes são a realização do interesse comum entre os Estados, os quais são egoístas racionais, ${ }^{57}$ buscando somente seu próprio ganho absoluto e não relativos. ${ }^{58}$ A coordenação é atrativa, mesmo na anarquia internacional, quando os Estados unilateralmente não conseguem alcançar resultados satisfatórios por meio de soluções ao estilo do Método Pareto ${ }^{59}$. Os neoliberais servem-se da Teoria dos Jogos ${ }^{60}$ para caracterizar a gama de interesses incluídos/contemplados pelos diferentes regimes. Portanto, regimes ajudam estados em seus próprios interesses, coordenando seus comportamentos e evitando resultados subótimos. ${ }^{61}$

${ }^{55}$ HASENCLEVER, Andreas; MAYER, Peter; RITTBERGER, Volker. Theories of international regimes. Cambridge: Cambridge University Press, 2004. p. 4.

${ }^{56}$ Ibidem, p. 4.

${ }^{57}$ Racionalidade implica que atores possuem preferências ordenadas e conscientes e que calculam custos e benefícios de diferentes alternativas de ação, a fim de maximizar seu proveito com vistas àquelas preferências. Egoísmo implica que a utilidade das funções é independente uma da outra: elas não ganham ou perdem utilidade só por conta dos ganhos e perdas de outros. Egoísmo não é uma categoria negativa expressa pela noção invejosa. Keohane apud Ibidem, p. 29.

${ }^{58}$ Ibidem, p. 4.

${ }^{59}$ Opção-Pareto, Eficiência-Pareto ou Ótimo-Pareto é uma noção econômica amplamente difundida nos assuntos estratégicos, principalmente, na Teoria dos Jogos. O Método Pareto implica que dentre várias opções de ação, se deve escolher a opção em que um dos componentes do sistema se beneficie da opção, contudo, sem que os demais membros sejam prejudicados.

${ }^{60}$ Teoria dos Jogos faz parte da matemática que estuda situações estratégicas nas quais atores escolhem diferentes opções na tentativa de maximizar o seu retorno. Inicialmente desenvolvida como ferramenta pra compreender comportamento econômico, a teoria dos jogos é hoje usada em diversos campos acadêmicos.

${ }^{61}$ HASENCLEVER, Andreas; MAYER, Peter; RITTBERGER, Volker. Theories of international regimes. Cambridge: Cambridge University Press, 2004. p. 4. 
Para Keohane, a anarquia das relações internacionais não pode ser entendida solitariamente, pois grande parte do comportamento estatal se dá pela falta de governo centralizado, mas é influenciado pelo grau de institucionalização entre os atores. ${ }^{62}$ Isso mina a visão Realista de que as instituições têm força cogente limitadíssima. A perspectiva singular Neoliberal é a de "institucionalismo contido": os regimes são efetivos e resilientes, mas, em seu modelo racional, as preferências e identidades dos atores são elementos exógenos e essencialmente não afetados pelas práticas institucionais e diretrizes. ${ }^{63}$

Segundo Stein, regimes são mais suscetíveis a produzir efeitos quando ações puramente autônomas, por parte dos Estados, podem levar a resultados desastrosos para todas as partes. Em outras palavras, quando ações individuais dos Estados claramente não permitem um nível necessário de coordenação internacional. ${ }^{64}$

Regimes ${ }^{65}$ internacionais proporcionam uma estrutura informacional, determinam uma base aceitável para redução de conflitos e formam uma base para se determinar o que é legítimo entre os atores e, consequentemente, moldam as expectativas nas interações. São capazes de interferir nas variáveis de poder e, logo, nas relações internacionais. A efetividade dos regimes varia conforme o grau de coesão das políticas com interesses comuns e distribuição de poder entre os membros. Instituições com valores sociais e sistemas políticos comuns tendem a ser mais efetivos, sendo assim, a política doméstica dos Estados tem substancial impacto nos regimes. ${ }^{66}$

\footnotetext{
${ }^{62}$ SARFATI, Gilberto. Teorias de relações internacionais. São Paulo: Saraiva, 2006. p. 155-156.

${ }^{63}$ HASENCLEVER, op. cit., p. 4.

${ }^{64}$ STEIN apud KRASNER, Stephen D. Structural causes and regime consequences: regimes as intervening variables. In: KRASNER, Stephen D. (Ed.). International regimes. Ithaca: Cornell University Press, 1983. p. 191.

${ }^{65}$ Regimes internacionais são "instituições com regras explicitamente acordadas por governos, que pertencem a um conjunto de assuntos específicos nas relações internacionais" KEOHANE apud HASENCLEVER, Andreas; MAYER, Peter; RITTBERGER, Volker. Theories of international regimes. Cambridge: Cambridge University Press, 2004. p. 12. Tradução nossa.

${ }^{66}$ KEOHANE, Robert O. International institutions: can interdependence work? In: ART, Robert J.; JERVIS, Robert. International politics. 7. ed. New York: Pearson Longman, 2005. p. 124.
} 
A terceira - Cognitivista ${ }^{67}$ - é influenciada pelas tradições de Grotius, e é elaborada por Raymond Hopkins, Donald Puchala, Oran Young, Robert Cox, Alexander Wendt, John G. Ruggie. Essa corrente acredita que os regimes internacionais são fenômenos difusos em todas as interações políticas. Em outras palavras, a criação dos regimes independe de vontade, no sentido estrito, isto é, tácita ou automaticamente. A simples interação ou relacionamento de atores na esfera internacional produz regimes. ${ }^{68}$

Portanto, qualquer padrão de comportamento dentro da esfera internacional gera expectativas generalizadas entre os atores, reprimindo qualquer tentativa antagônica à conduta padronizada. O que significa que nenhum comportamento nas relações internacionais pode persistir sem que um regime o respalde.

Dessa forma, Hopkins e Puchala afirmam que regimes estão em todas as esferas das relações internacionais, mesmo naqueles grandes conflitos por poder observados tradicionalmente como exemplos claros da anarquia internacional. Os tomadores de decisões sempre se veem obrigados por regras ou princípios que prescrevem ou proíbem certos comportamentos. ${ }^{69}$ Nessa concepção, os regimes são resultados de ações humanas, não tendo existência fora das relações sociais humanas. São produtos coletivos, não necessariamente formalizados, mas simples resultados das interações. E, embora sejam constituídos por vários atores, os atores individuais em regra são incapazes de alterar o regime.

Além disso, ao contrário da visão conceitual de Waltz, um realista, os seguidores de Grotius acreditam que até mesmo o sistema de balança de poder, na qual os Estados são pressionados a manter o equilíbrio de poder por ações repetitivas, é um exemplo de regime. ${ }^{70}$

${ }^{67}$ Cognitivista não é uma Escola da Teoria das Relações Internacionais. É a junção de inúmeras outras escolas, excluindo-se realistas e liberais, que possuem elementos comuns em suas análises sobre regimes. O que une os cognitivistas é a crítica a teorias racionalistas que tratam identidades e interesses estatais como elementos que lhes são dados exogenamente.

${ }^{68}$ KRASNER, Stephen D. Structural causes and regime consequences: regimes as intervening variables. In: KRASNER, Stephen D. (Ed.). International regimes. Ithaca: Cornell University Press, 1983. p. 187 e 192.

${ }^{69}$ HOPKINS; PUCHALA apud Ibidem, p. 192.

${ }^{70}$ Ibidem, p. 187 e 192. 
Hanseclever separa essa "escola” em duas: Cognitivistas Fracos e Cognitivistas Fortes. Ambas enfocam que a origem do interesse dos Estados é obtido em conexão com o papel fundamental das ideias. Esse processo é moldado por crenças normativas e causais; mudanças nas ideias podem mudar a política internacional.

Os primeiros, Cognitivistas Fracos, pretendem complementar a noção do racionalismo Liberal e Realista pelo incremento de que os regimes internacionais dependem da visão dos atores sobre um problema internacional, parte dessa percepção é produzida por crenças fundamentais ou normativas, parcialmente independentes do ambiente material (p.ex. distribuição de poder ou riquezas) dos atores. Os atores ainda são racionais e procuram maximizar seus benefícios, mas seu foco está nas formas prevalecentes de razão pelas quais os atores identificam preferências e opção de ação diante deles. ${ }^{71}$

Os Cognitivistas Fortes têm face totalmente sociológica, alternativa e não suplementar à noção racional dos atores. Para eles, a escola baseada em interesses não consegue visualizar a repercussão das práticas institucionalizadas. Nesse sentido, em ótica totalmente contrária às conclusões Realistas, as instituições têm desempenho fortíssimo nas ações dos atores. ${ }^{72}$

Estados não são unidades maximizadoras de benefícios, são role-players, representam um papel. Não se preocupam em como o conhecimento molda o interesse, mas sim com a existência e a natureza dos Estados. O conhecimento ou ideias não são elementos entre as necessidades estruturais/materiais e os resultados (ações). O conhecimento é parte fundamental da sua natureza, constitui os atores e os permite engajar em cooperação ou competição.

Compartilham a ontologia sobre a "sociedade internacional" da Escola Inglesa das Relações Internacionais, os Estados e os indivíduos conscientemente são constituídos em sociedade, nela dão forma e são moldados. Para eles, essa sociedade é cognitiva (expectativas mútuas, e crenças sobre comportamento legítimo ou ilegítimo), apesar de dependerem da continuação das suas práticas para manterem-se vivas. $\mathrm{O}$ conhecimento não somente afeta o interesse dos Estados, mas

\footnotetext{
${ }^{71}$ HASENCLEVER, Andreas; MAYER, Peter; RITTBERGER, Volker. Theories of international regimes. Cambridge: Cambridge University Press, 2004. p. 137.

${ }^{72}$ Ibidem, p. 5-6.
} 
forma sua identidade. Estados não são atores das relações internacionais porque possuem conhecimento que influencia sua decisão, mas são Estados juntamente porque há uma ideia comum de que existe um ambiente social internacional. Sendo assim, regimes podem ser vistos como uma estrutura cognitiva que alicerça a sociedade internacional em áreas específicas e permitem ações na sociedade. Os regimes são necessários para política internacional por ser um pré-requisito e não uma consequência racional. ${ }^{73}$

Resumo dos elementos determinantes das escolas:

\begin{tabular}{|l|l|l|l|}
\hline & Realismo & Liberal & Cognitivista \\
\hline Variável & Poder & Interesse & Conhecimento/Ideias \\
\hline $\begin{array}{l}\text { Orientação Meta- } \\
\text { teórica }\end{array}$ & Racionalista & Racionalista & Sociológica \\
\hline $\begin{array}{l}\text { Modelo } \\
\text { Comportamental }\end{array}$ & $\begin{array}{l}\text { Ganhos } \\
\text { Relativos }\end{array}$ & $\begin{array}{l}\text { Ganhos } \\
\text { Absolutos }\end{array}$ & Role-player \\
\hline $\begin{array}{l}\text { Grau do } \\
\text { Institucionalismo }\end{array}$ & Limitadíssimo & Limitado & Fortíssimo \\
\hline
\end{tabular}

Fonte: HASENCLEVER, Andreas; MAYER, Peter; RITTBERGER, Volker. Theories of international regimes. Cambridge: Cambridge University Press, 2004. p. 6. (Com adaptações).

\subsubsection{Teoria da estabilidade hegemônica}

O relacionamento entre a Teoria dos Regimes e a Teoria da Estabilidade Hegemônica é amplo. Alguns autores das escolas que tratam sobre relações internacionais veem que a efetividade dos regimes é totalmente alcançada conforme a capacidade de um ator hegemônico; já para outros, a teoria de regimes é uma alternativa à hegemonia. O tema também é discutido pelas escolas que tratam sobre regimes: realismo, liberalismo e cognitivismo. ${ }^{74}$

Pela ótica do estruturalismo realista sobre a estabilidade hegemônica, um sistema internacional estável requer liderança - em termos de poder. Isso significa que é indispensável que um Estado seja poderoso o suficiente para se impor sobre

${ }^{73}$ HASENCLEVER, Andreas; MAYER, Peter; RITTBERGER, Volker. Theories of international regimes. Cambridge: Cambridge University Press, 2004. p. 137-139.

${ }^{74}$ HASENCLEVER, Andreas; MAYER, Peter; RITTBERGER, Volker. Theories of international regimes. Cambridge: Cambridge University Press, 2004. p. 86. 
os demais (obrigando a contribuição dos custos por todos), e que esse esteja disposto a garantir o funcionamento das regras do sistema internacional, para que, dessa forma, haja anuência dos demais atores ao sistema internacional. E, portanto, estaríamos diante de um modelo de liderança coercitiva de Robert Gilpin. ${ }^{75}$

Logo, o papel dessa liderança é manter os regimes criados. Em outras palavras, o poder do Hegemon, ou liderança hegemônica, é usado para trazer resultados para o sistema como um todo. Ou seja, do argumento estruturalista conclui-se que a eficácia dos regimes internacionais é uma função direta da existência de um Hegemon. Desse modo, se a liderança se nega a aceitar um regime ou tem seu poder enfraquecido, também se enfraquecem os regimes (e também sua efetividade). Isso sugere que, sem liderança, os regimes podem ser facilmente burlados.

Nos termos de Kindleberger, o perigo não é o poder excessivo, mas pouquíssimo; não excesso de domínio, mas a volatilidade. É imprescindível um estabilizador, e somente um. O autor não é partidário do termo hegemon, alega que regimes são alternativas a uma liderança unilateral, e que a liderança pode ser atingida em termos benevolentes e não coercitivos. ${ }^{76}$ Segundo os realistas, quando o Hegemon não busca conquistar os Estados, mas simplesmente manter seu status quo, outros Estados também podem se beneficiar do sistema como um todo. ${ }^{77}$ Isso quer dizer que mesmo que um Estado busque seu interesse, algum proveito coletivo pode vir desse egoísmo estatal.

Contudo, constata-se que o Hegemon certamente será beneficiado nesse sistema, pois, como vimos anteriormente, a Teoria Realista assegura que todo Estado age segundo seus interesses próprios. Apesar disso, a mesma corrente também declara que para que o sistema cadenciado pelo Hegemon funcione, é preciso que esse distribua entre os demais atores bens coletivos, como, por exemplo, a estabilidade financeira e certeza jurídica ao sistema. Esses bens coletivos seriam responsáveis pela aderência e legitimidade do regime.

\footnotetext{
${ }^{75}$ Ibidem, p. 90-91.

${ }^{76}$ HASENCLEVER, Andreas; MAYER, Peter; RITTBERGER, Volker. Theories of international regimes. Cambridge: Cambridge University Press, 2004. p. 88-89.

${ }^{77}$ KEOHANE, Robert; NYE, Joseph. Power and interdependence. London: Logman, 2001. p. 38. Analisando o tema quanto à perspectiva realista.
} 
E, do mesmo modo, Keohane descreve que, para a visão economicista de estabilidade hegemônica, os "regimes econômicos estáveis requerem liderança - isto é, disposição para privar-se de ganhos iniciais por meio de barganhas que preservem o regime - e que é mais provável que um ator forneça tal liderança quando ele se enxerga como o maior consumidor dos benefícios de longo prazo produzidos pelo regime." 78

Contudo, mais amplamente para os Liberais, a teoria determinista baseada em termos de interesses e poder - é errônea, pois a política não é criada por um único hegemon. A existência de regimes não depende de uma hegemonia contínua, e a manutenção da ordem internacional não requer hegemonia. Para Keohane, o hegemon pode facilitar o regime, porém não é essencial para cooperação, e a cooperação pós-hegemonia é admissível. ${ }^{79}$

Em contrapartida à visão estrutural, Stein sugere que quando há um declínio do poder hegemônico, os incentivos à colaboração aumentam, pois os bens coletivos deixam de ser providenciados pelo Hegemon e os Estados buscam novas formas de manter a existência dos bens coletivos. Com isso, o sistema internacional se tornaria idêntico a um oligopólio, ao invés de ser um mercado livre. Os atores seriam mais conscientes de sua responsabilidade individual, ajustando suas ações para que não causassem danos aos demais atores. Os free-riders ${ }^{80}$ passariam a verificar a necessidade de arcar com os custos assim como os demais Estados. Em outras palavras, o declínio de um Hegemon resulta em regimes mais fortes e o interesse nacional de cada país é eficaz para manter um regime, independentemente da presença do Hegemon. ${ }^{81}$

\footnotetext{
${ }^{78}$ KEOHANE, Robert; NYE, Joseph. Power and interdependence. London: Logman, 2001. p. 38. Tradução nossa.

${ }^{79}$ KEOHANE, Robert O. International institutions: can interdependence work? In: ART, Robert J.; JERVIS, Robert. International politics. 7. ed. New York: Pearson Longman, 2005. p. 298-299.

${ }^{80}$ Em português, caronas. Termo utilizado para descrever Estados que se beneficiam dos ganhos resultantes de custos de outros atores sem que aqueles se comprometam a arcar também com os custos.

${ }^{81}$ STEIN apud KRASNER, Stephen D. Structural causes and regime consequences: regimes as intervening variables. In: KRASNER, Stephen D. (Ed.). International regimes. Ithaca: Cornell University Press, 1983. p. 199.
} 
Outra visão estrutural modificada é que a presença dos EUA foi essencial para manutenção do regime do pós-guerra. Veem nisso os indícios que mesmo na anarquia, quando um hegemon perde poder, os Estados estão suscetíveis a cooperar e não competir, pois após a criação de um regime não há incentivos para retirar-se de estratégias cooperativas e retornar a resultados subótimos. Na verdade, essa Teoria dos Jogos considera que, no dilema do prisioneiro, ${ }^{82}$ os jogadores só façam uma escolha e joguem uma única vez. Enquanto, na arena internacional, os Estados interagem inúmeras vezes, afetando assim o resultado final e suas estratégias. Verificando-se que os Estados devem interagir continuamente, esses atores nem sempre procuram estratégias cooperativas ao invés de egoístas. Ou seja, o melhor mecanismo para se manter um regime não é a presença do Hegemon, mas a reciprocidade e interação. ${ }^{83} ;{ }^{84}$

Também se afirma que a Teoria Hegemônica é inadequada para observar a política, os interesses e os assuntos domésticos, o que é indispensável quando se busca entender as relações internacionais. Antes disso, o Hegemon pode ser substituído por uma coalizão de atores que protegeriam o regime, como, por exemplo, as organizações internacionais. Os custos de se criar um novo regime são maiores do que a modificação de regimes antigos, por isso, regimes tendem a ser reformulados ou modificados ao invés de abandonados pelos Estados membros, quando há mudanças na esfera de poder ou quando o Hegemon se retira de um regime. ${ }^{85}$

\footnotetext{
${ }^{82}$ No dilema do prisioneiro, temos um exemplo clássico do problema da soma não zero na Teoria dos Jogos. Cada um dos dois jogadores envolvidos no dilema escolhe uma ação, independentemente do outro, e busca aumentar ao máximo suas vantagens sem conhecer as ações do outro jogador. Nesse contexto, joga-se uma única vez. A tendência é que cada jogador escolha o melhor para si individualmente, porém se escolhessem uma alternativa comum e favorável aos dois, ambos obteriam um resultado satisfatório para os dois. Infelizmente o dilema se constitui de modo que os jogadores tendem a não cooperar. Já quando se joga o mesmo jogo inúmeras vezes, os atores tendem a visualizar a cooperação.

${ }^{83}$ LITLLE, Richard. International regimes. In: BAYLIS, John; SMITH, Steve. The globalization of world politics. New York: Oxford, 2006. p. 380.

${ }^{84}$ Em relação ao tema, Richard Little explica o conceito de "shadow of the future" ou "sombra do futuro": The Prisoners' Dilemma presupposes that the game is only played once. But, in reality, because situations persist over time, it is more appropriate to think of the game being played over and over again. The shadow of the future looms over the player, affecting their strategic calculations. Because the game will be on future occasions, it becomes worthwhile taking a risk and pursuing a collaborative strategy [...]. Ibidem, p. 380.

${ }^{85}$ KEOHANE, Robert; NYE, Joseph. Power and interdependence. London: Logman, 2001.
} 
Essas críticas fazem com que a noção Realista sobre o papel do Hegemon e a respeito da ordem internacional seja substituída por uma adequação ou acomodação do realismo pelo estruturalismo modificado, um paradigma mais cheio de nuances. Outra questão observada por essa corrente é que não necessariamente regimes dependam de interesses compartilhados, mas podem emergir da discórdia e da confusão. Sugerem os estruturalistas modificados que há compartilhamento de custo muito mais do que benefícios no processo de interdependência dos Estados nas relações internacionais, o que também é verdadeiro para os regimes.

Nesse contexto, os cognitivistas ou os grocianos, influenciados pelo "reflexivismo" não racionalista, que os difere dos estruturalistas, propõem que os interesses, ações, percepções e valores são determinados pelo processo de socialização que transforma a "sombra do futuro" ${ }^{86} \mathrm{em}$ uma "sombra das instituições." Isso significa que os interesses dos Estados e suas escolhas não são necessariamente anteriores à criação de um regime. Ou seja, os atores não estão somente condicionados à anarquia das relações internacionais, mas também estão condicionados pelas regras, normas, princípios e padrões de comportamento advindos da interação entre eles. ${ }^{87}$

Por isso, Young afirma que os regimes são formados basicamente por três padrões de comportamento: espontâneos, no qual os regimes emergem da convergência de expectativas entre vários atores; negociado, quando regimes são acordos explícitos; e imposto, quando um regime é externamente imposto aos atores. ${ }^{88}$

Para o neogramsciano Cox, a Teoria Realista da Estabilidade Hegemônica é falha, pois foca demasiadamente em forças materiais. O autor prefere uma al-

86 Ver nota 82 .

87 KRASNER, Stephen D. Structural causes and regime consequences: regimes as intervening variables. In: KRASNER, Stephen D. (Ed.). International regimes. Ithaca: Cornell University Press, 1983. p. 196.

88 YOUNG apud Ibidem, p. 196. 
ternativa na qual deixa de ser um item "explicatório ${ }^{89 "}$ e passa a ser explicado. ${ }^{90} \mathrm{~A}$ Teoria Clássica não é capaz de demonstrar as origens da dominação embutidas no conceito de hegemonia.

Tratando-se de hegemonia, o trabalho de Cox deve muito ao de Gramsci, que se voltava ao espaço doméstico da política italiana a fim de vislumbrar o cenário internacional. Para Gramsci, não há dúvida de que as relações internacionais seguem as relações sociais fundamentais: assim como as relações dentro dos Estados podem ser traçadas pelos movimentos sociais, a política internacional ou ordem mundial, descrita como mudanças na balança geopolítica e na estratégia militar, também reflete mudanças fundamentais nas relações sociais. No entanto, para Gramsci, o Estado é a entidade fundamental das relações internacionais, isto é, o local onde o conflito social acontece e onde as hegemonias são construídas. ${ }^{91}$

Nesse contexto, Cox nota que uma ordem hegemônica internacional é baseada em dois níveis. Primeiro, no internacional, onde há, provavelmente, um Estado dominante materialmente, ainda que por si, essa dominância não baste para criar uma hegemonia no cenário internacional. O segundo nível é o doméstico, que depende da obtenção pelo(s) Estado(s) dominante(s) do respaldo das camadas sociais dominantes dos demais Estados. Em outras palavras, a hegemonia, internacionalmente, é mantida pelo sucesso das práticas sociais das elites dominantes e da influência que elas exercem no restante da sociedade global. Essa prática, descrita como revolução passiva é que legitima e apoia a base de uma hegemonia. ${ }^{92}$ Além

89 “Teorias explicativas procuram formular as explicações, entendidas como leis ou regras sobre o que são as coisas e como elas funcionam (relacionamento entre as coisas). Por outro lado, as teorias que buscam entender afirmam que todo o teórico que constrói uma teoria o faz carregado de seus preconceitos e crenças e isso afeta como ele vê o assunto a ser analisado; assim, ao contrário de vertente anterior, que crê em uma realidade objetiva que se possa explicar, esta vê que a realidade é socialmente construída." SARFATI, Gilberto. Teorias de relações internacionais. São Paulo: Saraiva, 2006. p. 28.

90 HASENCLEVER, Andreas; MAYER, Peter; RITTBERGER, Volker. Theories of international regimes. Cambridge: Cambridge University Press, 2004. p. 200.

${ }^{91}$ COX, Robert W. Gramsci, hegemony and international relation: an essay in method. In: GILL, Stephen. Gramsci, historical materalism and international relations. Cambrigde: Cambrigde University Press, 1993. p. 58.

${ }^{92}$ Idem. Rumo a uma concepção pós-hegemônica de ordem mundial: reflexões sobre a relevância de Ibn Kaldun. In: ROSENAU, James N; CZEMPIEL, Ernst-Otto. Governança sem governo: ordem e transformação na política mundial. Brasília: Ed. UnB, 2000. p. 194. 
disso, Cox ainda inclui a questão econômica, política e cultural para formação da hegemonia:

Hegemonia no nível internacional não é pois meramente uma ordem entre Estados. É uma ordem dentro da economia com um modo de produção dominante que penetra em todos os países e se liga a outros modos de produção. Também é um complexo de relações sociais conectadas a classes sociais de diferentes países. Hegemonia mundial é descritível como uma estrutura, uma estrutura econômica, e uma política; e não pode ser simplesmente uma dessas coisas, mas deve ser todas as três. Hegemonia mundial, ademais, é expressa em normas, instituições e mecanismos universais que estabelecem regras gerais de comportamento para os Estados e para aquelas forças da sociedade civil que atuam através das fronteiras nacionais - regras que dão suporte ao modo de produção dominante. ${ }^{93}$

Independentemente dos diversos exames, quanto ao papel do Hegemon nos regimes internacionais, é comum entre as três visões teóricas que qualquer regime é refém da distribuição de poder nas relações internacionais. Para Young, por exemplo, os regimes impostos tendem a se desintegrar quando há mudanças nas esferas de poder. Já Hopkins e Puchala sugerem que regimes altamente politizados e difusos, porém tendenciosos quanto a seus valores, são altamente suscetíveis a uma transformação radical quando a distribuição de poder se modifica. Essa visão enfatiza que o declínio ou perda de poder do Hegemon não depende de sua capacidade em promover os bens coletivos, mas em influenciar ou controlar as estratégias dos Estados mais fracos, o que resulta por consequência óbvia em mudanças no regime. ${ }^{94}$

Essa visão também é compartilhada por estruturalistas como Krasner, porém com ênfase no hard power ao invés do soft power. Durante os anos 1970 e 1980, muitos observavam que os regimes internacionais iam contra os interesses do terceiro mundo. Levando isso em consideração, os Realistas declaravam indiscutivel-

${ }^{93}$ COX, Robert W. Gramsci, hegemony and international relation: an essay in method. In: GILL, Stephen. Gramsci, historical materalism and international relations. Cambrigde: Cambrigde University Press, 1993. p. 61-62.

${ }^{94}$ KRASNER, Stephen D. Structural causes and regime consequences: regimes as intervening variables. In: KRASNER, Stephen D. (Ed.). International regimes. Ithaca: Cornell University Press, 1983. p. 200. 
mente que o único antídoto para essa situação seria uma mudança na balança de poder contra os países tidos como ocidentais. ${ }^{95}$

\subsection{A dinâmica dos regimes ambientais em reflexo com a teoria dos regimes internacionais}

Existem hoje mais de 130 regimes multilaterais sobre meio ambiente. Alguns são letras mortas, mas vários, conforme estudado por Hass ou Levy, pelo menos ajudaram parcialmente a resolver os problemas enfrentados. ${ }^{96}$ Portanto, os autores refletem sobre a teoria básica dos regimes e suas diferenças quanto ao issue area. Essa seção propõe explicar a natureza singular e comum entre regimes internacionais, já mencionados desde o início do trabalho, e os regimes ambientais.

As formações dos regimes ambientais internacionais, em termos doutrinários, não se diferem dos demais regimes internacionais, isto porque a estrutura básica, apesar de conter peculiaridades, é formada pelos mesmos moldes dos outros regimes. Os regimes ambientais são mecanismos jurídicos/políticos sobre os quais as expectativas dos atores convergem em administrar o meio ambiente.

Entende-se que os regimes são arranjos institucionais com o objetivo de administrar relativamente o processo de interdependência global, creditando-se o meio ambiente como mais um dos entrelaçamentos que constituem a interdependência. Aponta-se que, da mesma forma em que se cria um regime para o comércio internacional, segurança internacional, finanças internacionais, cria-se um regime para o meio ambiente como, por exemplo, o regime de mudanças climáticas.

Contudo, conclui-se que, mesmo o meio ambiente sendo um elemento da interdependência, há de se salientar que existe, pelo menos dentro de uma perspectiva Realista, uma hierarquização da agenda internacional e que, certamente, dentro dessa, o meio ambiente não é um tema priorizado sobre as demais.

Portanto, em primeira análise, principalmente em termos jurídicos, os regimes internacionais são iguais; não há diferença em sua conceituação. Aparente-

\footnotetext{
${ }^{95}$ LITLLE, Richard. International regimes. In: BAYLIS, John; SMITH, Steve. The globalization of world politics. New York: Oxford, 2006. p. 380.

${ }^{96}$ GREENE, Owen. Environmetal issues. In: BAYLIS, John; SMITH, Steve. The globalization of world politics. New York: Oxford, 2006. p. 362.
} 
mente, o objetivo de se criar um regime para reger um determinado setor da interdependência é o mesmo de outro. Contudo, a motivação, o empenho, a expectativa, os custos, os atores, o consenso, as teorias, a conscientização, os interesses e as ideologias, dentre outros fatores, são responsáveis por relativizar o tema ambiental nas relações internacionais.

\section{Efetividade dos regimes ambientais internacionais}

O principal objetivo desta parte do trabalho é demarcar parâmetros para que se possa verificar o que se especula ser efetividade dos regimes ambientais e as formas possíveis de análise de efetividade. Busca-se uma conceituação e metodologia genérica que permita uma análise posterior do tema e de meios pelos quais outrem possa recorrer a insights metodológicos para análises próprias sobre a efetividade dos inúmeros regimes ambientais internacionais.

Será examinado aquilo que se entende sobre efetividade, eficácia, compliance, enforcement e implementação dos regimes ambientais. Esses termos são indispensáveis para o entendimento de efetividade dos regimes ambientais. Para tal apreciação se recorrerá a autores que estão empenhados no estudo dos regimes ambientais internacionais como, por exemplo, Oran Young, Arild Underdal, Edith Brown Weiss, dentre outros.

Conclusivamente, pretende-se demarcar possíveis critérios para auferir a efetividade, demonstrar o tema dos regimes e constituir uma ferramenta teórica para avançar-se sobre a efetividade dos regimes ambientais.

\subsection{0 que é efetividade e como mensurá-la}

Efetividade dos regimes internacionais em geral, em termos amplos, é a capacidade de algo atingir o objetivo estratégico para o qual foi criado. ${ }^{97}$ Da mesma forma, um regime ambiental internacional pode ser considerado efetivo desde que seja bem sucedido em realizar um conjunto de funções predeterminadas ou

\footnotetext{
${ }^{97}$ HASENCLEVER, Andreas; MAYER, Peter; RITTBERGER, Volker. Theories of international regimes. Cambridge: Cambridge University Press, 2004. p. 2.
} 
quando é capaz de solucionar o problema para qual foi estabelecido. ${ }^{98}$ Também se define efetividade como: "uma questão da contribuição que as instituições fazem para solucionar os problemas os quais motivam os atores a investir tempo e energia necessários." ${ }^{99}$

Entretanto, essas definições são extremamente elusivas, pois são vários os modos de se julgar os efeitos produzidos por um regime. E, por consequência, os resultados dessas avaliações são inúmeros, tendo em vista a variedade de abordagens utilizadas para mensurar a efetividade de um regime. Logo, o tema será tratado abaixo, enfatizando-se que se trata da efetividade dos regimes ambientais, todavia o que for apresentado também é plausivelmente, com certas mudanças, utilizável em mensuração da efetividade dos regimes como um todo.

Quando se averigua a efetividade dos regimes ambientais internacionais, fatalmente é preciso definir um modo de mensurá-la para finalmente constatar se, de fato, um regime é efetivo. Para tal averiguação, recorre-se inicialmente a algumas perguntas que auxiliarão a se formularem premissas necessárias à conclusão do tema central do trabalho.

Por que um regime internacional é mais bem sucedido em seus objetivos que outros? Ou, por que alguns regimes são capazes de causar grande impacto positivo nas ações humanas enquanto outros tendem ao fracasso? Por que um modelo de regime aplicado em conjunto é efetivo para solucionar um tipo de problema ambiental, enquanto para outros não é efetivo? O que os difere? O que torna um regime efetivo? Essas perguntas são compartilhadas pelos mais diversos campos de estudos das relações internacionais e são temas discutidos em vários setores da comunidade.

A essas perguntas responde-se com uma resposta dupla: por causa do problema em si (problem itself) e por causa da capacidade de solucionar o pro-

${ }^{98}$ UNDERDAL, Arild. One question, two answers. In: MILES, Edward L. et al. Environmental regime effectiveness: confronting theory with evidence. Massachusetts: The MIT Press, 2002. p. 4.

${ }^{99}$ YOUNG, Oran R.; LEVY, Marc A. The Effectiveness of international environmental regimes. In: YOUNG, Oran R. (Ed.). The effectiveness of international environmental regimes: causal connections and behavioral mechanisms. Cambridge, Massachusetts, London, England: The MIT Press, 1999. p. 3. 
blema (problem-solving capacity). Primeiramente, alguns dos problemas são de solução mais fácil. Por exemplo: quando possuem unanimidade quanto as suas soluções e são intelectualmente menos complicados ou politicamente mais benignos, ou seja, possuem elementos que possibilitam uma solução mais simples. Em segundo, alguns esforços são mais bem sucedidos, isso porque alguns mecanismos institucionais aplicados na solução do problema são mais fortes do que outros. ${ }^{100}$

Entretanto, toda avaliação de efetividade é resultado de um critério de comparação, não necessariamente entre dois regimes, e que, ao se comparar algo, é preciso responder a três perguntas: (1) Qual e o que é objeto (raio de ação e estágio) da pesquisa? (2) Este objeto será comparado a qual padrão? (3) Qual será a abordagem para comparar o objeto ao padrão? ${ }^{101}$ É isso que precisa ser definido pelo cientista e será descrito adiante.

\subsubsection{Objeto}

Primeiramente, o objeto em questão deve ser um regime. É simples escolher qual regime se pretende estudar. Contudo, dentro do objeto, deve-se estipular qual é o raio de ação - quais resultados obtidos pela criação do regime serão avaliados (direta, indireta, ou ambos); e qual etapa (estágio) do regime pretende ser observada.

\subsubsection{Raio de ação}

Por um lado, a análise dos efeitos diretos permitirá avaliar os resultados das ações institucionais indicadas no arcabouço do regime. Por outro lado, a apreciação dos efeitos indiretos permitirá uma compreensão extensiva das ações relacionadas ao regime, mas que não são, fundamentalmente, resultados diretamente atribuídos a sua existência.

${ }^{100}$ UNDERDAL, Arild. One question, two answers. In: MILES, Edward L. et al. Environmental regime effectiveness: confronting theory with evidence. Massachusetts: The MIT Press, 2002. p. 3.

${ }^{101}$ Ibidem, p. 5. 
Para Young, efetividade direta ou indireta dos regimes é uma questão da extensão das cadeias de causalidade que conectam o regime ao comportamento em questão. "Efeitos diretos são relacionados a redes curtas de causalidade, efeitos indiretos são mais longos. Na maioria dos casos, efeitos diretos são centrados no comportamento envolvendo a compliance ${ }^{102} \mathrm{com}$ as regras e participação em atividades programadas." ${ }^{103}$ Já os efeitos indiretos são todos os atos, fatos, ações e reações que, mesmo não sendo resultantes do regime em si, são favoráveis aos objetivos estipulados pelo regimes.

\subsubsection{Estágio do regime}

Em segundo lugar, dentro do objeto, é importante delimitar qual é o estágio do regime que se pretende estudar: na metodologia deve constar se será estudado o regime desde que a sociedade científica constatou o problema ambiental, passando pela tomada de consciência da sociedade das nações, pela negociação, formação, implementação e resultados finais do regime.

Underdal, para simplificar esses estágios dos regimes, fez uma divisão em três categorias temporais: (1) output, estágio no qual o regime é formado quando são assinados os acordos e medidas tomadas pelos Estados; (2) outcome, período quando medidas adotadas pelos Estados passam a afetar a sociedade; (3) impact, estágio em que são evidentes as mudanças/efeitos no meio ambiente. ${ }^{104}$

Para este trabalho, adotaremos uma forma de estágios similar a de Underdal $^{105}$, mas para isso utilizaremos uma classificação mais ampla dos estágios de um

${ }^{102}$ Para definição de compliance ver adiante.

${ }^{103}$ YOUNG, Oran R.; LEVY, Marc A. The Effectiveness of international environmental regimes. In: YOUNG, Oran R. (Ed.). The effectiveness of international environmental regimes: causal connections and behavioral mechanisms. Cambridge, Massachusetts, London, England: The MIT Press, 1999. p. 12. Tradução do autor.

${ }^{104}$ UNDERDAL, Arild. One question, two answers. In: MILES, Edward L. et al. Environmental regime effectiveness: confronting theory with evidence. Massachusetts: The MIT Press, 2002. p. 5-7.

${ }^{105}$ Apesar de ser possível que haja outra divisão dos estágios por outro autor, encontramos somente a divisão de Underdal. Não obstante, observamos que uma nova divisão poderia clarificar o tema, e, por isso, propomos a nossa própria divisão dos estágios baseando-se naquilo que observamos nas pesquisas sobre regimes. 
regime. Os estágios serão divididos em cinco categorias: (a) negociação, (b) formalização (c) implementação, (d) compliance, (e) efetividade. ${ }^{106}$

No primeiro estágio, na negociação, o regime ainda não existe, é um período que se inicia quando os Estados reconhecem que existe um problema a ser solucionado. Sendo assim, passam a negociar com o intuito de formalizar a criação de um regime para solucioná-lo.

As negociações são aquelas que ocorrem entre autoridades governamentais, mas que, em alguns casos, há presença de atores não-governamentais, tais como, grupos de interesses e representantes da sociedade em geral.

O parâmetro utilizado para determinar o início e o final da etapa de negociação é, respectivamente, quando os Estados buscam negociar por meio de vias diplomáticas e o momento em que eles emitem o final act. ${ }^{107}$

O segundo estágio, o da formalização, é definido pelo procedimento da assinatura do tratado por uma autoridade competente do país signatário. Esse texto possui natureza jurídica e está sujeito a leis dos tratados. É o documento base que determinará as obrigações que cada ator deve tomar no intento de solucionar o problema ambiental em questão. Isso significa que este documento é a pedra fundamental de um regime e nele estão contidas as primícias que formam ou formarão princípios, normas, regras e procedimentos de tomada de decisão, sobre os quais as expectativas dos atores convergem ou convergirão em uma determinada área temática, as quais as partes devem esforçar-se em cumprir.

Vigência significa que uma norma está em vigor. É uma das características essenciais que uma norma precisa ter para produzir efeitos no mundo real. Uma norma só é válida quando apresenta todos os seus elementos constitutivos de acordo com ordenamento jurídico em vigor. Quanto a isso, Miguel Reale comenta que

${ }^{106}$ Existem etapas anteriores a negociação, mas, neste trabalho, não se pretende analisar o que se pode chamar de etapas pré-regime ou pré-negociação internacional. O ponto inicial para se analisarem os regimes ambientais internacionais, neste trabalho, será a partir do momento em que os Estados buscam negociar, em conjunto, para solucionar um problema ambiental.

${ }^{107}$ Esse termo significa ato final. É uma simples declaração, normalmente emitida nas negociações multilaterais ou bilateraias, que relata o negociado, mas não cria obrigações legais, podendo conter anexos com manifestações políticas unilaterais dos Estados. LANG, W. International environmental negotiations. Geneva, Switerland: UNITAR, 1997. p. 8. 
“[...] vigência ou validade formal é a executoriedade compulsória de uma regra de direito, por haver preenchido os requisitos essenciais à sua feitura ou elaboração."108

Além disso, no Direito, para uma norma ser vigente, é preciso verificar o momento em que ela entra em vigor para os destinatários. Sobre isso se aponta que:

A vigência da norma pode ser ou não simultânea a sua existência. Há normas que já são exigíveis desde o momento de sua criação, e há normas que só estarão vigentes após um certo período de tempo. Portanto, quando uma lei é criada, as partes podem escolher o momento de sua vigência, fazendo-a valer no mesmo dia, ou após algum tempo. Para esse período dá-se o nome de vacatio legis. ${ }^{109}$

Para Kelsen, a norma é algo a mais que um simples arcabouço lógico formal; na realidade, atribui-se à norma o poder mandamental, isto é, o dever ser com o objetivo de regulamentar a conduta humana. ${ }^{110}$ Telles Junior resume de maneira clara o pensamento da natureza da norma jurídica:

A norma jurídica não é descritiva de um comportamento efetivamente mantido, ou de um estado das coisas efetivamente existente. Ela é, isto sim, a fórmula do comportamento que deve ser mantido, em determinada circunstância, ou o modelo de um almejado estado das coisas. Ela é uma indicação do caminho, e não o relato do caminho percorrido. Ela não descreve o que é, mas o que deve ser. Ela não é norma do ser, mas do dever-ser. ${ }^{111}$

É importante lembrar que no Estado Democrático de Direito, "a lei é o único instrumento por meio do qual os Estados podem definir e expressar preocupações ambientais fundamentais [...]"112, e apesar dos instrumentos jurídicos não

${ }^{108}$ REALE apud CALSING, Renata de Assis. Possibilidades e limites da efetividade do direito internacional ambiental: uma análise da CITES, Convenção da Basiléia e Protocolo de Quioto. Brasília: [s.n.], 2005. p. 74.

${ }^{109}$ CALSING, Renata de Assis. Possibilidades e limites da efetividade do direito internacional ambiental: uma análise da CITES, Convenção da Basiléia e Protocolo de Quioto. Brasília: [s.n.], 2005. p. 74.

${ }^{110}$ KELSEN apud SARAIVA, Paulo Lobo. Estrutura lógica da proposição jurídica. Revista Vox Legis, [S.1.], v. 151, jul. 1981. p. 4.

111 TELLES JUNIOR, Goffredo. Iniciação na ciência do direito. São Paulo: Saraiva, 2001. p. 59.

${ }^{112}$ KISS, Alexandre. Introduction to international environmental law. Genebra, Suíça: UNITAR, 1997. p. 7. Tradução nossa. 
produzirem sempre uma efetividade perfeita, a sua eliminação geraria um caos na proteção ambiental.

O terceiro estágio refere-se à implementação. Segundo a Convenção de Viena de 1969, tratados são obrigatórios para as partes contratantes as quais devem implementá-los em boa fé. ${ }^{113}$

A implementação "refere-se a medidas que os Estados adotam para tornar acordos internacionais efetivos na legislação doméstica." 114 Também significa que agora os resultados obtidos na negociação devem ser transformados em ações. É um estágio dividido em duas esferas: internacional e doméstica.

$\mathrm{Na}$ internacional, os Estados devem cooperar para implementar todo arcabouço de instituições jurídicas internacionais capazes de tornar o tratado efetivo, como, por exemplo, um secretariado capaz de monitorar a efetividade do regime.

Na doméstica, busca-se tornar o tratado efetivo na legislação doméstica, ou seja, é um processo de internalização do acordo internacional. Inicia-se no ato de ratificação do tratado. No caso brasileiro, em regra, os tratados negociados internacionalmente devem ser aprovados pelo legislativo para que tenham força de lei.

Nesse estágio, portanto, ficam mais claras as diferenças entre os processos de ratificação adotados internamente pelos atores, que podem ser mais curtos ou mais longos, ter maiores ou menores custos políticos e sociais, para serem concretizado. Sendo assim, a demora ou negativa da ratificação pode trazer problemas para implementação dos regimes.

Pode-se afirmar que a implementação é um passo político que resulta em criação de instituições e mecanismos jurídicos que possibilitam o próximo passo, compliance. No nível doméstico, é caracterizado pelo momento em que as obrigações estabelecidas por normas internacionais são recepcionadas pelo ordenamento jurídico nacional. Em outras palavras, é a criação ou adequação de princípios, normas, regras, procedimentos de tomada de decisão, programas de governo e instituições com a finalidade de fazer com que todas as ações de um Estado venham corroborar os objetivos do regime.

${ }^{113}$ Convenção de Viena. Artigo 26: Princípio Pacta Sunt Servanda.

${ }^{114}$ WEISS, Edith Brown; JACOBSON, Harold K. Engaging countries: strengthening compliance with international environmental accords. Massachussets: The MIT Press, 2000. p. 4. 
Destarte, é importante que os Estados, ao assinarem, também estejam dispostos a implementar as regras internacionais em seu domínio. Ou seja, que não apenas sejam partes formais do acordo, mas que sejam partes realmente interessadas em efetivá-lo. Isso porque existem casos em que os Estados assinam acordos internacionais sem qualquer intuito de efetivá-los, tornam-se apenas signatários, e, em muitos casos, acabam tornando-se free-riders, beneficiando-se da criação do regime sem tomar parte nos custos envolvidos.

O quarto estágio é o de compliance. ${ }^{115}$ Ao se examinar compliance das partes do tratado, busca-se verificar se esses países de fato, no mundo do ser, aderiram às provisões do acordo internacional e dos mecanismos implementados no nível doméstico. ${ }^{116} \mathrm{Ou}$ seja, é examinado se a conduta do ator está em conformidade com as normas estipuladas no tratado. O que difere implementação de compliance é que, na primeira, as normas internacionais devem ser internalizadas no dever ser doméstico; já no compliance os atores devem agir no mundo real em conformidade com o dever ser.

Além disso, examinando o compliance, busca-se avaliar se as ações humanas no mundo real estão em conformidade com as obrigações impostas pelo tratado e pelos instrumentos jurídicos implementados pelo Estado. Compliance vai além da implementação: verifica-se se os governos e se os indivíduos estão de fato seguindo com aquilo que foi estipulado no tratado e no Direito Interno.

Contudo, medir compliance de um tratado é difícil:

Pode-se dizer que as medidas necessárias de compliance são definidas pelo tratado, que exporá em seus parágrafos as ações que deverão ser seguidas. Medir compliance de uma norma é algo extremamente difícil, uma vez que ela é quase sempre imperfeita. Contudo, [...] o mundo dos fatos não se iguala ao mundo das normas, já que essas são criações abstratas que guiam o mundo real, sem que seja imprescindível a efetivação de todos os aspectos

${ }^{115}$ Compliance é uma palavra inglesa que aparentemente não possui tradução direta ao português. Significa o grau em que as normas devem ser implementadas e executadas em critérios iguais aos acordados em um tratado. Sua definição é muito próxima ao de eficácia social das normas. Porém, não será considerada sinômina no texto, pois eficácia social terá outra conotação quando se comenta sobre abordagens legais.

${ }^{116}$ WEISS, Edith Brown; JACOBSON, Harold K. Engaging countries: strengthening compliance with international environmental accords. Massachussets: The MIT Press, 2000. p. 4. 
regulamentados. Assim, a conformidade da efetivação das regras ambientais internacionais deve ser analisada em um limite do possível, conforme a finalidade do regime. ${ }^{117}$

Para que um Estado esteja em compliance com um tratado, é preciso que seu governo adote medidas domésticas de enforcement, ${ }^{118}$ o que significa que o Estado deve forçar o cumprimento das normas, especialmente, por meio das sanções aos atores estatais e não estatais dentro do território doméstico.

Para o bom andamento dos regimes ambientais internacionais, é importantíssimo instituir normas efetivas: em primeiro lugar, isso envolve a implementação de normas e depois assegurar que os Estados venham a cumpri-las. Entretanto, como foi mencionado no início deste trabalho, os meios de se obter compliance em um regime internacional diferem dos mecanismos utilizados pelos Estados em seu território: a comunidade internacional não tem poder de polícia, impossibilitando o enforcement. Isso impede a implementação de normas e sanções das maneiras como as conhecemos em nossos territórios. Dessa forma, é evidente a necessidade de se utilizarem mecanismos e técnicas que estimulem compliance, e que possam atrair os Estados a anuirem a valores ambientais. O professor Kiss cita formas em que se pode conseguir esse objetivo: persuasão, pressão da opinião pública, assistência financeira e técnica, boa redação legal, remoção de obstáculos legais, dentre outros. Isso é, estimular ações que levem ao compliance, ao invés de impor sanções pelo uso da força policial. ${ }^{119}$ E mesmo assim, a compliance dos atores sociais e estatais pode não atingir os objetivos de solucionar um problema específico em questão, sendo assim, é preciso avaliar o próximo estágio.

O último estágio corresponde aos impactos finais de um regime. Como mencionado antes, um regime ambiental pode ser considerado efetivo desde que seja bem sucedido em realizar um conjunto de funções predeterminadas no tratado ou quando é capaz de solucionar o problema para qual foi estabelecido.

${ }^{117}$ CALSING, Renata de Assis. Possibilidades e limites da efetividade do direito internacional ambiental: uma análise da CITES, Convenção da Basiléia e Protocolo de Quioto. Brasília: [s.n.], 2005. p. 130.

${ }^{118}$ Termo sem tradução para o português. Fica próximo da definição do poder de polícia e executabilidade.

${ }^{119}$ KISS, Alexandre. Introduction to international environmental law. Genebra, Suíça: UNITAR, 1997. p. 57. 
A efetividade, em regra, está ligada aos meios empregados no processo contínuo desses estágios, mas não necessariamente é exclusividade desse processo, pois, como também se relatou, existem elementos externos ou indiretamente relacionados ao regime que podem colaborar ou não com seus objetivos.

Apesar da etapa de compliance ser altamente relacionada com a efetividade de um regime, salvo exceções, não se pode considerá-las idênticas. Em alguns casos, um regime que consegue mudar a conduta humana, via compliance, pode ser considerado efetivo mesmo que não tenha solucionado o problema ambiental em questão. Porém nos regimes que buscam solucionar o problema ambiental, o estado biofísico do meio ambiente é que determina se o regime é efetivo ou não. Isso expressa que todos os membros de um regime podem executar o estágio de compliance perfeitamente, todavia, esses esforços podem ser ineficazes para se alcançar o resultado ambiental desejado. Isto é, o regime alcança os objetivos traçados, contudo, no plano real, na natureza, não soluciona o problema ambiental em questão.

Os demais estágios de um regime são prelúdios que visam ao objetivo final de tornar o regime efetivo. Analisando-os, é possível concluir o porquê de um regime ser ou não ser efetivo. Mesmo essa análise sendo dispensável em alguns casos, tal averiguação pode orientar na descoberta dos erros e acertos que motivaram o grau de efetividade de um regime. Isso não quer necessariamente dizer que a efetividade é uma consequência direta dos estágios anteriores, mas, com certeza, algumas causas podem ser relacionadas a esse processo.

Aproveitando a capacidade de se averiguar os impactos dos regimes, os atores, conforme sua avaliação, podem reformular ou criar propostas quando notam que as ações foram incapazes de concretizar os resultados predeterminados ou manter os instrumentos existentes quando resultaram em impactos positivos.

\subsection{Padrão}

Em temos de conhecimento geral, um padrão é a escolha subjetiva de um elemento como marco ideal reconhecido de forma objetiva como parâmetro para futuras mensurações. Underdal, raciocinando em termos metodológicos, assegura 
que avaliar a efetividade de um determinado regime implica em comparar ${ }^{120}$ um objeto - o regime - a um padrão. ${ }^{121}$ Esse padrão deve ser o ponto de referência.

Sobre esse padrão, Underdal declara que regimes internacionais são normalmente avaliados: (1) em termos de quão bem desempenham suas funções comparativamente ao estado em que as coisas estariam em sua ausência; ou (2) em termos de sua habilidade para solucionar o problema para o qual foram criados para lidar." ${ }^{22}$ Nesse sentido, o padrão é um "ponto de referência”, sobre o qual será comparado o regime. Esse padrão pode ser: a efetividade alcançada por outro regime, o estado hipotético em que se encontraria o problema caso não houvesse o regime em questão, ou qualquer outro marco ideal escolhido pelos avaliadores.

\subsection{Abordagens}

Previamente foi mencionado que efetividade demanda a contribuição das instituições criadas para solucionar o problema as quais estimulam os atores a adotarem medidas que ajudem na questão.

Contudo, para se verificar se esse processo encontra-se ativo é imprescindível verificá-lo sobre critérios de análise, pois uma análise, por mais ampla que

${ }^{120}$ Em visão pessoal, atualmente, diversos analistas de relações internacionais e de Direito Internacional têm analisado, comparativamente, o Regime de Ozônio, um exemplo de regime bem sucedido, com o Regime de Mudanças Climáticas. A análise comparativa é uma opção satisfatória em certos pontos, entretanto, muitas vezes, se abordado levianamente, comparar regimes resulta apenas em conclusões das diferenças entre regimes, sem qualquer utilidade prática. Por outro lado, torna-se algo útil quando se busca maximizar a efetividade de um regime, utilizando-se do processo de aprendizado proporcionado pelo estudo comparativo. Afinal, a política internacional é notoriamente um processo de aprendizagem contínuo. Dentro dessa perspectiva, na realidade, isso significa que cada ator muda suas ações conforme novas informações são encontradas no cenário internacional. Nos casos em que os regimes possuem objetos ou problemas de natureza diversa, isso faz com que a pesquisa entre regimes se resuma a comparações cheias de nuances as quais são dispensáveis para responder a uma das perguntas fundamentais sobre efetividade: o regime é efetivo? Não desapreciamos a comparação, mas informamos que nem sempre os resultados são os esperados.

${ }^{121}$ UNDERDAL, Arild. One question, two answers. In: MILES, Edward L. et al. Environmental regime effectiveness: confronting theory with evidence. Massachusetts: The MIT Press, 2002. p. 4-5.

${ }^{122}$ Ibidem, p. 8. 
deseje ser, não consegue equacionar todas as variáveis possíveis que incidem sobre um regime. Normalmente, a escolha da abordagem utilizada é de caráter subjetivo, no entanto, a abordagem vale-se de uma conceituação de efetividade como critério objetivo. A abordagem busca estabelecer a melhor maneira de relacionar um dado objeto ao seu padrão ideal. Portanto, varia muito segundo os pressupostos assumidos pelas diferentes teorias ou ciências que investigam um referido regime.

Young conseguiu uma síntese capaz de expor adequadamente os principais campos de estudos válidos tanto para os teóricos das Relações Internacionais quanto para os de Direito Internacional ao abordarem a efetividade dos regimes. Segundo o autor, os analistas dos temas usam majoritariamente as seguintes abordagens para determinar a efetividade de um regime: solução do problema, legal, econômica, normativa e política. Como outros autores compartilham, omitem, ou mudam minimamente essas divisões, entende-se que sejam adequadas ao estudo em tela.

A abordagem de solução de problemas é a capacidade que um regime alcança em resposta a um problema específico: poluição transfronteiriça, gestão hídrica, mudanças climáticas. Ou seja, a efetividade do regime vai depender do grau em que se extingue ou mitigue o problema que motivou sua criação. ${ }^{123}$

O que torna essa abordagem pouco confiável é que o regime interage com inúmeras variantes que independem da sua criação. Exemplificando: quando um Estado não é membro de um determinado regime, mas a sociedade civil deste Estado age de forma a colaborar para solucionar um problema ambiental, independente da posição formal de seu país, isso pode ajudar o regime como um todo a solucionar o problema. No entanto, não foi o regime que diretamente obteve resultados, mas foi a sociedade civil que passou empenhar-se. Às vezes, isso compromete a avaliação do regime, pois não se tem clara definição se foi o regime, ou não, o motivo da solução do problema. Por não fornecer, quase sempre, a capacidade de apurar qual fator contribuiu decisivamente, mas apenas se a solução foi atingida ou não, a abordagem de solução de problemas pode ser omissa. Sendo assim, inviabi-

${ }^{123}$ YOUNG, Oran R.; LEVY, Marc A. The Effectiveness of international environmental regimes. In: YOUNG, Oran R. (Ed.). The effectiveness of international environmental regimes: causal connections and behavioral mechanisms. Cambridge, Massachusetts, London, England: The MIT Press, 1999. p. 4-6. 
liza a curva de aprendizagem tão necessária para o conhecimento do processo de evolução dos regimes.

A abordagem legal, em contrapartida, considera um regime efetivo se os compromissos acordados entre as partes estão sendo cumpridos como, por exemplo, se cada país está tomando as devidas medidas institucionais previamente acordadas em contrato para reduzir a poluição marítima ou emissão de gases na atmosfera. Para Young, efetividade legal depende do cumprimento das obrigações contratuais:

Uma definição legal da efetividade poderia considerar que as medidas da efetividade de um regime são o grau ao qual as obrigações contratuais são atingidas - as regras são cumpridas, políticas modificadas, programas iniciados, e assim por diante [...] ao Contrário da definição do problem solving, a abordagem legal provê uma medição relativamente franca porque a efetividade é definida quanto a obrigações escritas em um tratado. ${ }^{124}$

Essa abordagem não busca verificar se o regime está sendo eficaz em reduzir, por exemplo, a poluição marítima, mas se as partes estão tomando as medidas legais acordadas em tratado. $\mathrm{O}$ resultado desse método implica que um regime pode ser legalmente efetivo sem que, na realidade, ele esteja contribuindo ou solucionando por completo o problema em questão.

Para se averiguar a efetividade de um regime por meio do ponto de vista legal, é importante focar-se em três estágios fundamentais de um regime: na formalização, porque é imperativo que se conheça o texto legal fundamental de um regime para se distinguir se as partes estão exercendo suas obrigações; na implementação, pois essa etapa informará se as partes estão tomando as medidas legais necessárias para aplicar o que foi pactuado no acordo internacional; no estágio de compliance, já que é nesse estágio que se observa se as condutas humanas estão de acordo com as regras do tratado.

${ }^{124}$ YOUNG, Oran R.; LEVY, Marc A. The Effectiveness of international environmental regimes. In: YOUNG, Oran R. (Ed.). The effectiveness of international environmental regimes: causal connections and behavioral mechanisms. Cambridge, Massachusetts, London, England: The MIT Press, 1999. p. 4. 
Para que uma norma seja efetiva, é preciso que tenha eficácia social: ${ }^{125}$

[...] a eficácia social das normas, é o cumprimento efetivo do Direito por parte da sociedade, que reconhece as normas e as cumprem, concretizando assim os comandos das normas, fazendo com que seus preceitos incidam efetivamente na vida social. ${ }^{126}$

Encontra-se na Abordagem Econômica uma mutação das duas outras abordagens já mencionadas. A noção econômica incorpora uma variável ao conceito de efetividade, buscando-se não só a efetividade legal ou solução do problema, mas também se essa é a mais economicamente viável para os atores. Em outras palavras, não basta ser efetiva, é preciso ter custo mínimo e não incidir sobre outros custos onerando-os. ${ }^{127}$

Ademais, os interesses econômicos dos Estados e os custos envolvidos na criação e manutenção de um regime representam elementos que podem determinar a efetividade de um regime. "Quanto maior for o custo de adaptação das regras ambientais, maior será a resistência na adoção de suas normas.”128

Nesse sentido, um dos motivos para que um Estado adira a um regime é a socialização dos custos que teria em separado para solucionar determinado problema em comum e quantos mais Estados ingressam e contribuem, tanto menor é o custo para as partes integrantes do regime. Aderir a um regime é uma maneira de internalizar os custos de uma situação ambiental que, de outra maneira, não poderia contar com o engajamento e responsabilização comum de todos os atores, principalmente para os casos em que apenas um deles é responsável pela deterioração do ambiente com efeitos que incidem sobre os demais.

${ }^{125}$ Para alguns autores, efetividade ou eficácia social são sinônimos. Renata Calsing afirma que o termo eficácia social significa "a efetiva realização da norma jurídica no seu meio social, transformando em realidade aquilo que a norma prevê." CALSING, Renata de Assis. Possibilidades e limites da efetividade do direito internacional ambiental: uma análise da CITES, Convenção da Basiléia e Protocolo de Quioto. Brasília: [s.n.], 2005. p. 80.

${ }^{126}$ BARROSO, Luís Roberto apud Ibidem, p. 79.

${ }^{127}$ YOUNG, Oran R.; LEVY, Marc A. The Effectiveness of international environmental regimes. In: YOUNG, Oran R. (Ed.). The effectiveness of international environmental regimes: causal connections and behavioral mechanisms. Cambridge, Massachusetts, London, England: The MIT Press, 1999. p. 4-6.

${ }^{128}$ CALSING, Renata de Assis. Possibilidades e limites da efetividade do direito internacional ambiental: uma análise da CITES, Convenção da Basiléia e Protocolo de Quioto. Brasília: [s.n.], 2005. p. 161. 
A quarta abordagem é a Normativa, na qual a efetividade é verificada em termos de princípios. Portanto, para um regime ser efetivo, é preciso atender certos princípios tais como: justiça, equidade, participação popular, democracia. ${ }^{29}$

Contudo, quando se estipula princípios como padrões de avaliação, encontra-se um grande obstáculo prático, pois todos esses princípios são por demais elusivos. Almejar esses princípios é imprescindível nas relações internacionais, entretanto, são responsáveis por grandes questões filosóficas que fogem à análise pragmática dos regimes ambientais internacionais. Não que seja incorreta essa metodologia, mas é complexa demais e, em alguns casos, pode resultar em exames por demais vagos.

A Abordagem Política define efetividade como uma função desempenhada pelo regime em mudar o comportamento dos atores em suas políticas de forma que suas ações passem a colaborar com o andamento do processo internacional para solução de um problema ou maior fruição do conjunto de mecanismos designados para regular determinada área. ${ }^{130}$

Essa abordagem não inviabiliza as demais abordagens, isto é, caso, dentro da análise política, se escolha analisar se um problema foi solucionado, se há cumprimento do teor legal do regime, se princípios normativos são observados, se existem intuições que contribuem para minimização dos custos, não há qualquer empecilho, desde que, esses elementos façam parte de um conjunto maior, em que se verifique a efetividade em mudar o comportamento dos atores no cenário internacional.

129 YOUNG, Oran R.; LEVY, Marc A. The Effectiveness of international environmental regimes. In: YOUNG, Oran R. (Ed.). The effectiveness of international environmental regimes: causal connections and behavioral mechanisms. Cambridge, Massachusetts, London, England: The MIT Press, 1999. p. 4-6.

${ }^{130}$ YOUNG, Oran R.; LEVY, Marc A. The Effectiveness of international environmental regimes. In: YOUNG, Oran R. (Ed.). The effectiveness of international environmental regimes: causal connections and behavioral mechanisms. Cambridge, Massachusetts, London, England: The MIT Press, 1999. p. 4-6. 


\section{Quadro sinóptico: TEORIA + Metodologia = EFETIVIDADE}

\section{[TEORIA (Objeto +Abordagem+Padrão)] = EFETIVIDADE}

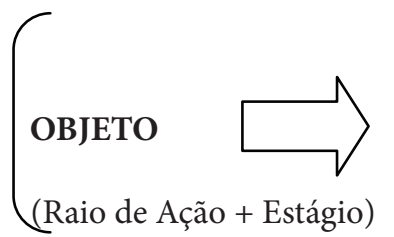

\section{ABORDAGEM}

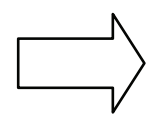

PADRÃO

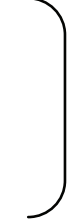

\section{Conclusão}

Cada perspectiva das Escolas Teóricas das Relações Internacionais relatada observa o fenômeno dos regimes internacionais de uma forma diferente. Apresenta uma variedade de conceitos e entendimentos sobre o tema, ao mesmo tempo em que os problemas internacionais, tais como os ambientais, são desafios internacionais factuais.

Os regimes internacionais são uma resposta encontrada para esses desafios e para a crise de eficiência da governança global. Mas os elementos culturais, econômicos, valores, ideias, poderes e interesses determinam o processo e resultados de qualquer ação internacional. Muito daquilo que é chamado de política ambiental internacional é correlata ao desenvolvimento e implementação dos regimes. Portanto, avaliar a efetividade desses instrumentos de natureza política e jurídica é o mesmo que avaliar, ao fim, os patamares da governança global. Independentemente dos interesses, poderes ou ideias envolvidas, os regimes ambientais são científicos o suficiente para se demonstrarem indispensáveis para a cooperação na anarquia. Se as instituições não são a força motriz por trás do processo de solução dos problemas, são ao menos uma variável digna de verificação.

Sendo assim, os analistas refletem sobre o papel desempenhado pelos regimes internacionais no processo de causar ou solucionar os problemas internacionais. A causa principal de discordância sobre essa reflexão reside nas diversas formas de pesquisa, conceituação e metodologias envolvidas. Entretanto, é possível que a utilização de questões comuns orientadas para avaliar as instituições possa promover um debate entre as teorias de regimes. 
Apesar de não se crer na existência de uma possível síntese teórica universal, entende-se que um debate positivo pode emergir na ampliação e aproximação dos resultados no debate interparadigmático final, desde que confrontados com as análises empíricas físicas do meio ambiente.

A questão ambiental permite que haja uma verificação do problem solving, um fator científico e objetivo, muitas das vezes externo a teorias. A própria condição física do meio ambiente é observável mais claramente pelas ciências exatas que formam subsídio na análise sobre efetividade. Isso viabiliza, portanto, tanto o debate intraescolas como interescolas.

Ressalva-se que a escolha do objeto, das abordagens e do padrão é influenciada pelo campo de formação ou ação do cientista, bem como por suas escolhas quanto à cosmovisão que possui ou professa da realidade, a qual é normalmente expressa em valores congruentes com alguma das principais Teorias das Relações Internacionais.

Portanto, por exemplo, um jurista marxista cognitivista, buscando um entendimento sobre a abordagem econômica de um regime ambiental, chegará a conclusões diferentes comparadas a uma abordagem também econômica realizada por um realista racionalista. Sendo assim, se compararmos os estudos em termos metateóricos, é possível desconstruir ou reconstruir o argumento de ambos, observar suas bases para compreensão do tema, compará-las com os resultados científicos apresentados pelas ciências de base físicas e chegar à obtenção dos pontos comuns ou divergentes entre eles. Contudo, sem a utilização do reconhecimento metateórico da análise e dos resultados empíricos do problem solving pouco será conquistado. Não é possível comparar estudos econômicos de um marxista com um liberal ou com um realista, em busca do que parece ser correto sobre regimes quando não se tem uma noção das teorias envolvidas no tema. E tampouco, quando não há clara noção de qual metodologia se segue. Nesse sentido, acredita-se que possa haver uma suposta síntese no âmbito de um diálogo interparadigmático, e que jamais haverá qualquer diálogo, mas competição, se os autores tentarem dialogar diretamente no nível de metodologias/conclusões e não teorias/metodologias/conclusões.

Também é lembrado que é preciso uma divisão do trabalho por realistas, liberais ou cognitivistas para que observem cada metodologia por sua teoria, para que 
inúmeros campos sejam examinados. Contudo, existem divergências ontológicas e epistemológicas entre as escolas, isso inviabiliza uma síntese plena dos argumentos. Contudo, aqui se apresentou uma visão idealista no sentido de que é possível uma integração nos estudos para maior entendimento do tema. Em outras palavras, a divisão e não competição para entendimento do tema será mais frutífera se respeitados os entendimentos teóricos, por isso a relevância da bibliografia discutida no texto.

Como foi exposto desde o início de nosso trabalho, o basilar nesta pesquisa é a apresentação, mesmo que breve, do que são regimes internacionais e de uma metodologia para pesquisa da efetividade de regimes ambientais. Diante do exposto, em suma, propõe-se uma esfera pública de discussão do tema, um debate entre os analistas, utilizando de suas conclusões, objetos, abordagens, padrões e teorias, se orientado de forma vertical e horizontal. Isto é:

(1) de cima para baixo (vertical), analisar as teorias que determinam a escolha de padrões, objetos e abordagens específicas;

(2) de baixo para cima (vertical), tomar os resultados encontrados pelos cientistas de uma teoria de regimes e compará-los com os resultados de cientistas sob a sombra de teoria diversa;

(3) horizontal, checar possibilidades de uma orientação comum, porém, “jamais" universal entre as teorias; ${ }^{131}$

(3) obter as conclusões dos autores e possíveis semelhanças ou discrepâncias teóricas, verificando qual delas ou qual junção delas consegue ter maior respaldo dos dados físicos encontrados para justificação de suas teses iniciais;

(4) por último, após a junção de inúmeros estudos com essa conotação apresentada, ter-se-á uma gama de elementos comuns que podem ser aproveitados, de forma complementar, ou enfatizando um determinado ponto de vista, seja para justificação ou descrédito de uma determinada avaliação de efetividade. Sendo indispensável que haja o maior interesse possível dos analistas em termos de troca de informações e trabalhos para, a partir daí, se verificar onde residem as chaves da crise de eficiência e governança global. Por exemplo, veja o quadro abaixo como ilustração simplória:

\footnotetext{
${ }^{131}$ Para maior entendimento do que se apresenta nesse item ver: HASENCLEVER, Andreas; MAYER, Peter; RITTBERGER, Volker. Theories of international regimes. Cambridge: Cambridge University Press, 2004. p. 211-224.
} 


\begin{tabular}{|c|c|c|}
\hline 莕 & 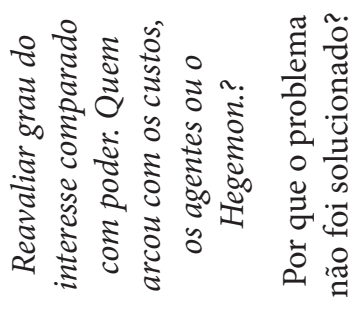 & 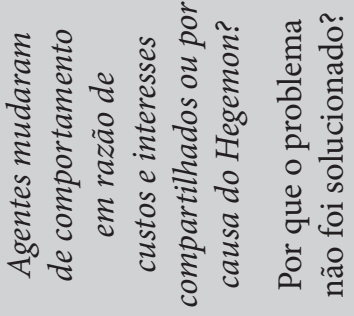 \\
\hline 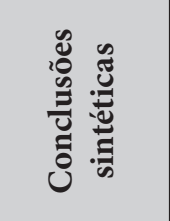 & 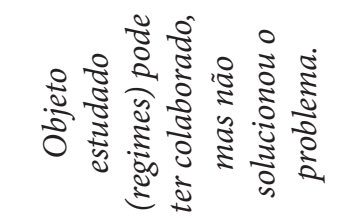 & 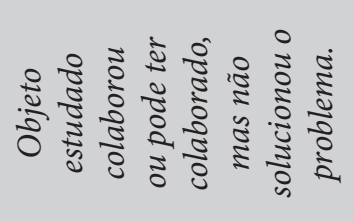 \\
\hline 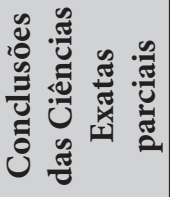 & 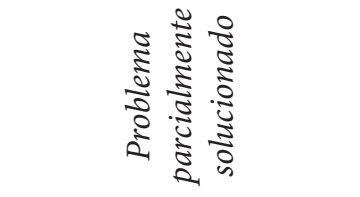 & 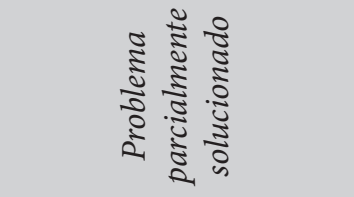 \\
\hline 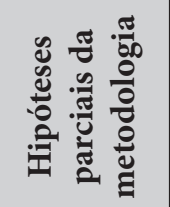 & 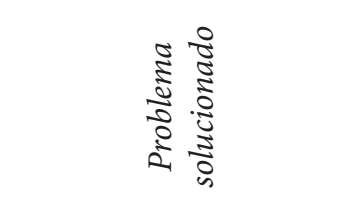 & 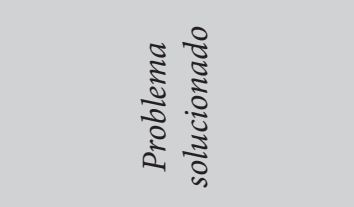 \\
\hline 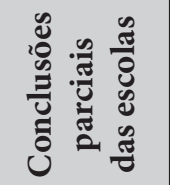 & 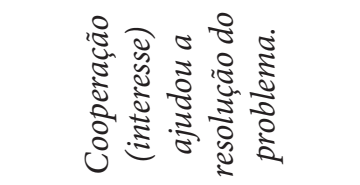 & 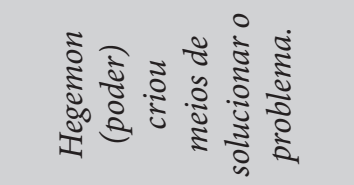 \\
\hline 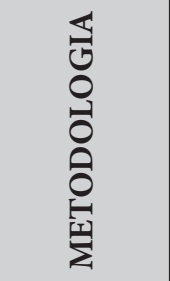 & 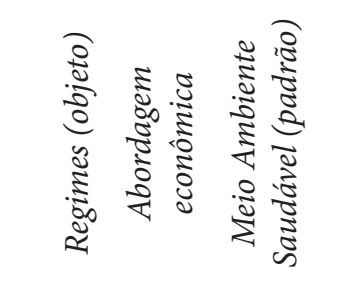 & 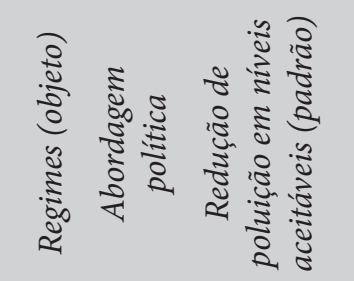 \\
\hline 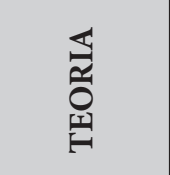 & 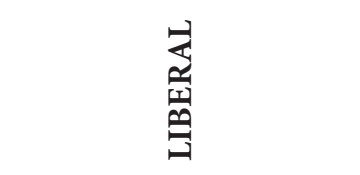 & 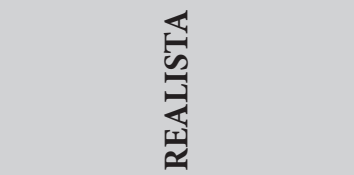 \\
\hline
\end{tabular}


No mais, o advento dos regimes internacionais tem contribuído no processo da efetividade dos regimes ambientais. Isso porque, apesar de já haver a preocupação com o meio ambiente em outras épocas, a formação de uma consciência ambiental sólida, em termos que envolvam tanto a sociedade civil quanto à sociedade política, é um elemento da pós-modernidade. É, na realidade, o resultado da fusão de vários fatores de um bloco histórico, dentre os quais, o agravamento da degradação ambiental, a ampliação do conhecimento e do consenso técnico, científico e tecnológico sobre o meio ambiente, e, principalmente, a consequência de reformas políticas que buscam maior participação popular nas tomadas de decisões governamentais. Nesse contexto da interação, é a questão chave para entender o processo dos regimes: observar e analisar a forma das dinâmicas entre sociedades, Estados e o processo de gestão global do meio ambiente, e conhecer quais são as transformações proporcionadas pelos regimes. Não somente observar a agenda ambiental internacional, mas as práticas dos povos, nações e Estados em consequência do grau "institucionalismo" que as envolve.

\section{International environmental regimes: theory and effectiveness methodology}

\section{Abstract}

This article aims to analyze international regimes and to present a methodology orientated to offer a background for future analyses on environmental regime effectiveness. First, the nature of international regime is scrutinized by three lenses of International Relations: Neorealism, Neoliberalism and Cognitivism. Finally, the article presents categories and methodological options for evaluating the effectiveness of international environmental regimes.

Keywords: International regimes. International environmental law. Effectiveness. Hegemonic stability theory. International law. International institutions.

\section{Referências}

BARROS-PLATIAU, Ana Flávia; VARELLA, Marcelo Dias; SCHLEICHER, T. Rafael. Meio ambiente e relações internacionais. Revista Brasileira de Política Internacional, [S.1.], p. 100-130, 2004. 
CALSING, Renata de Assis. Possibilidades e limites da efetividade do direito internacional ambiental: uma análise da CITES, Convenção da Basiléia e Protocolo de Quioto. Brasília: [s.n.], 2005.

CARR, Edward H. Vinte anos de crise. 2. ed. Brasília: Ed.Unb, 2001.

CASTELLS, Manuel. Communication, power and counter-power in the network Society. International Journal of Communication, v. 1, 2007, p. 238-266. Disponível em: <http://www.manuelcastells.info/en/obra_02.htm>. Acesso em: 16 fev. 2009.

CASTELLS, Manuel. Fim do milênio. 4. ed. São Paulo: Paz e Terra, 2007.

. Global governance and global politics. Political Science \& Politics, v. 38, n. 1, p. 9, jan. 2005. Disponível em: <http://www.manuelcastells.info/ en/obra_02. htm >. Acesso em: 16 fev. 2009.

. Manuel Castells: depoimento [maio de 2001]. Entrevistador: Harry Kreisler. Califórnia, EUA, 2001. Conversation with History: Institute of International Relations, UC Berkeley. Disponível em: <http:// globetrotter.berkeley.edu/people/ Castells/castells-con0.html>. Acesso em: 16 fev. 2009.

. O poder da identidade. 3. ed. São Paulo: Paz e Terra, 2002.

. Sociedade em redes. 3. ed. São Paulo: Paz e Terra, 1999.

COX, Robert W. Gramsci, hegemony and international relation: an essay in method. In: GILL, Stephen. Gramsci, historical materalism and international relations. Cambrigde: Cambrigde University Press, 1993.

DEVETAK, Richard. Critical theory. In: BURCHILL, Scott; LINKLATER, Andrew. Theories of international relations. New York: St. Martin's Press, 1995.

GREENE, Owen. Environmetal issues. In: BAYLIS, John; SMITH, Steve. The globalization of world politics. New York: Oxford, 2006.

GRIECO, Joseph. M. Anarchy and the limits of cooperation. In: KEGLEY JR, Charles W. Controversies in international relations theory: realism and its neoliberal challenge. USA: Thompson, 1995.

GRIFFITHS, Martin. 50 grandes estrategistas das relações internacionais. São Paulo: Contexto, 2004. 
HASENCLEVER, Andreas; MAYER, Peter; RITTBERGER, Volker. Theories of international regimes. Cambridge: Cambridge University Press, 2004.

HASS, P. M. Introduction: epistemic communities and international policy coordination. International organization, [S.1.], v. 46, n. 1, 1992.

HOBSBAWN, Eric. Era dos extremos. São Paulo: Companhia das Letras, 2008.

HOLSTI, Ole R. Theories of international relations and foreign policy: realism and its challengers. In: KEGLEY JR, Charles W. Controversies in international relations theory: realism and its neoliberal challenge. California, USA: Thompson, 1995.

KEOHANE, Robert O. International institutions: can interdependence work? In: ART, Robert J.; JERVIS, Robert. International politics. 7. ed. New York: Pearson Longman, 2005.

KEOHANE, Robert; NYE, Joseph. Power and interdependence. London: Logman, 2001.

KISS, Alexandre. Introduction to international environmental law. Genebra, Suíça: UNITAR, 1997.

KUHN, Thomas Samuel. The structure of scientific revolution. 3. ed. Chicago, IL: University of Chicago Press, 1996.

KRASNER, Stephen D. Structural causes and regime consequences: regimes as intervening variables. In: KRASNER, Stephen D. (Ed.). International regimes. Ithaca: Cornell University Press, 1983.

KRASNER, Stephen. Sovereignty: organized hypocrisy. New Jersey: Princeton Press, 1999.

LANG, W. International environmental negotiations. Geneva, Switerland: UNITAR, 1997.

LEVY, Marc; YOUNG, Oran; ZÜRN, Michael. The study of international regimes. [S.l.: s.n.], 1995.

LITLLE, Richard. International Regimes. In: BAYLIS, John; SMITH, Steve. The globalization of world politics. New York: Oxford, 2006. 
NIEBUHR, Reinhold; HARRY, Davis R.; GOOD, Robert C. (Ed.). Reinhold Niebuhr on politics. New York: Charles Scribner's Sons, 1960.

A crise mundial e a responsabilidade dos Estados Unidos. São Paulo: Dominus Editora, 1964.

REUS-SMIT. International law. In: BAYLIS, John; SMITH, Steve. The globalization of world politics. New York: Oxford, 2006.

SANTANA, Leonardo Dias. As mudanças climáticas e os regimes internacionais. Brasília: [s.n.], 2004.

SARAIVA, Paulo Lobo. Estrutura lógica da proposição jurídica. Revista Vox Legis, [S.1.], v. 151, jul. 1981.

SARFATI, Gilberto. Teorias de relações internacionais. São Paulo: Saraiva, 2006.

TELLES JUNIOR, Goffredo. Iniciação na ciência do direito. São Paulo: Saraiva, 2001.

UNDERDAL, Arild. One Question, Two Answers. In: MILES, Edward L. et al. Environmental regime effectiveness: confronting theory with evidence. Massachusetts: The MIT Press, 2002.

VIOTTI, Paul R; KAUPI, Mark V. International relations theory: realism, pluralism, Globalism, and Beyond. 3. ed. Boston: Prentice Hall, 1998.

WEISS, Edith Brown; JACOBSON, Harold K. Engaging countries: strengthening compliance with international environmental accords. Massachussets: The MIT Press, 2000.

YOUNG, Oran R. Why is there no unified theory of environmental governance? Presented at the commons in an age of globalization, the ninth Conference of the International Association for the Study of Common Property, Victoria Falls, Zimbabwe, June 17-21, 2002. Disponível em: <http://dlc.dlib.indiana.edu/ archive/00000943/>. Acesso em: 19 fev. 2009.

YOUNG, Oran R.; LEVY, Marc A. The Effectiveness of international environmental regimes. In: YOUNG, Oran R. (Ed.). The effectiveness of international environmental regimes: causal connections and behavioral mechanisms. Cambridge, Massachusetts, London, England: The MIT Press, 1999. 